\title{
OS PADRÕES DE ELEMENTOS TERRAS RARAS (ETR) E A AFINIDADE GEOQUIIMICA KOMATIIITICA DOS XISTOS MAGNESIANOS E ROCHAS ASSOCIADAS DO COMPLEXO CAMBAIZINHO, SÃO GABRIEL/RS
}

\author{
MARCUS V. D. REMUS*, LÉO A. HARTMANN* M MLTON L.L. FORMOSO*
}

\begin{abstract}
THE RARE-EARTH ELEMENT (REE) PATTERNS AND THE KOMATIITIC GEOCHEMISTRY AFFINITY OF THE MAGNESIAN SCHISTS AND ASSOCIATED ROCKS FROM THE CAMBAINHO COMPLEX, SÃO GABRIEL/RS. The largest part of the mafic-ultramafic rocks from the Sul-Riograndense Shield are localized in its western region. In the Arroio Cambaizinho, São Gabriel, these lithologies occur intercalated with metasedimentary rocks, the whole sequence metamorphosed in the amphibolite facies of regional metamorphism. The mafic-ultramafic sequence is constituted by serpentinites, magnesian schists, metabasalts, amphibolites and metagabbros; these correspond to basic-ultrabasic flows and or hypabissal intrusions. Chemical analysis of trace elements on 43 samples, including rare-earth elements on 22 samples, indicate derivation of the magnesian schists from komatiites; the mantle of the area was rather enriched in incompatible elements. The associated amphibolites correspond to light rare-earth element enriched magnesian tholeiites. The serpentinites correspond mostly to komatiitic cumulates extensively transformed and/or a residual metasomatic rock. the parental magmas of this sequence were extrated from an incompatibleelement enriched mantle and extruded on an early continental crust.
\end{abstract}

Keywords: Ultramafic rocks, magnesian schists, komatiites, rare earth element geochemistry.

\begin{abstract}
RESUMO No setor oeste do Escudo do Rio Grande do Sul, localiza-se a maior pane das rochas máficas e ultramáficas metamorfizadas de idade pré-cambriana do Rio Grande do Sul. Na regiâo do Arroio Cambaizinho, São Gabriel, essas rochas ocorrem na forma de intercalações, no interior de sequências metassedimentares, em equilíbrio na fácies anfibolito do metamorfismo regional. A sequência máfico-ultramáfica, constituída por serpentinitos, xistos magnesianos variados, metabasaltos, anfibolitos e metagabros, representam derrames básico/ultrabásicos e/ou intrusões ígneas de pequena profundidade. Análises químicas para elementos traços (Cr, Ni, V, Co, Zn, Cu, Zr, Rb, Sr, Ba, Y, Ga e Nb), em cerca de 43 amostras, e elementos terras raras (ETR), em 22 amostras da sequência máfico-ultramáfica, indicam a derivação dos xistos magnesianos a partir de komatiitos enriquecidos em elementos incompatíveis. Os anfibolitos associados apresentam afinidades com suítes toleíticas magnesianas e possuem também enriquecimento em elementos terras raras leves. Os serpentinitos correspondem, em sua maioria, a cumulados de derrames komatíticos intensamente transformados e/ou a resíduos de metassomatismo. As lavas que deram origem às rochas desta sequência foram extraídas de um manto enriquecido em elementos incompatíveis e estravasaram numa crosta continental pré-existente.
\end{abstract}

Palavras-chave: Rochas ultramáficas, xistos magnesianos, komatiítos, geoquímica dos elementos terras raras.

INTRODUÇÃOO Desde a descoberta da existência de lavas ultrabásicas no Rio Komatii, na região de Barberton (África do Sul), pelos irmãos Viljoen (1969a, b), muito esforco tem sido empreendido em quase todas as áreas de escudos antigos, no sentido de indentificar litologias assemelhadas.

O grande interesse revelado pelos estudiosos dessas rochas não reside somente no seu significado petrogenético e geoquímico, mas igualmente na importância económica e tectônica dos cinturões metamórficos que as contêm (Viljoen \& Viljoen 1982). Embora o reconhecimentos dessas litologias, a partir de presença de texturas e/ou estruturas vulcânicas/vulcanoclásticas, esteja firmemente estabelecido em várias ocorrências estudadas (Viljoen \& Viljoen 1969a, b, Nesbitt 1971, Pyke et al 1973, Arndt et al 1977, Sabóia \& Teixeira 1980, Montalvão et al 1981, Donaldson 1982, Padilha et al 1985, Schrank 1986, entre outros), um dos grandes problemas enfrentados, ainda hoje, recai na identificação dessas rochas ultrabásicas extrusivas em terrenos metamórficos-polideformados.

Em algumas situações favoráveis, essas litologias podem ser identificadas. Exemplo disso, são os cinturões metamórficos, nos quais as transformações de trama e mineralogia dos derrames podem ser acompanhadas progressivamente, desde as rochas preservadas, quase inalteradas (zonas de baixa intensidade de deformação), até áreas com intensa reorganização textural e mineralógica. Nestas últimas zonas, onde, de modo geral, o metamorfismo já é de grau médio e a deformação mais intensa, os komatiitos são transformados em anfibolitos, xistos magnesianos variados e serpentinitos (Peredery 1979, Viljoen et al 1982, Jolly 1982, entre outros).

No Escudo do Rio Grande do Sul, especialmente em sua fração oeste, rochas ultramáficas metamorfizadas, pertencentes à serie magnesiana, foram originalmente descritas $\mathrm{e}$ interpretadas num contexto metassomático, na década de 60, e denominadas de Formação Cerro Mantiqueira e Formação Cerro do Ouro (Gõni 1962).

A origem dessas rochas foi também relacionada às associações ofiolíticas (Jost 1966, Szubert et al 1977, Ribeiro \& Fantinel 1978, Ribeiro \& Lichtemberg 1978, Wildner 1990, entre outros).

Posteriormente, alguns desses autores reinterpretam tais associações rochosas e reconhecem certas similaridades entre estes terrenos e os greentones belts encontrados no Brasil e em outros continentes (Nardi \& Hartmann 1979, Hartmann \& Nardi 1983, Fragoso César 1980, Ribeiro 1981, Jost \& Hartmann 1984, Remus \& Hartmann 1986, Koppe et al 1985, Koppe \& Hartmann 1988, entre outros). 
A afinidade geoquímica das rochas ultrabásicas, especialmente dos elementos maiores encontrados nas ocorrências de Palmas (Garcia \& Hartmann 1981, Chemale Jr. 1982), Ibaré (Naumann 1985), Caçapava do Sul (Bittencourt \& Hartmann 1984), permitiu associa-las a magmas de composição komatítica. Entretanto, texturas e/ou estruturas indicativas de origem extrusiva para as mesmas foram descritas somente nas regiões de Pinheiro Machado (Ribeiro 1981) e São Sepé (Zarpelon 1986).

Na região do Arroio Cambaizinho, município de São Gabriel, RS, as rochas máficas e ultramáficas, até então interpretadas como sendo parte de uma associação ofiolítica parcial constituída pelos complexos ultramáficos e gabróico, eram consideradas de origem intrusivas (Szubert et al. 1977). A reinterpretação da geologia desta região permitiu atribuir origem extrusiva e afinidade geoquímica komatiítica para partes dessas litologias (Remus 1990). Nesse sentido, mapeamentos geológicos, realizados pelo autor sénior, resultaram na definicão do Complexo Cambaizinho, que representa a continuidade norte de um cinturão supracrustal polideformado, de forma geométrica aproximadamente linear, com orientação NNE, que se estende desde a região do Passo do Ivo, localizado mais a sul do complexo, até a região objeto deste trabalho. Na região do Arroio Cambaizinho, esse cinturão está representado pelas sequências metassedimentares e máfico-ultramáfica. O mapa geológico, bem como a estratigrafia da área, estão sintetizados na figura 1.

A sequência metassedimentar, referida preteritamente à Formação Vacacaí, do Grupo Porongos (Gõni et al. 1962, Jost \& Villwock 1966), consiste em xistos e gnaisses quartzo-feldspáticos dominantes, anfibolitos bandados e quartzitos e metapelitos subordinados, derivados de sedimentos elásticos.

As rochas da sequência máfico-ultramáfica, consideradas como pertencentes à Formação Cerro Mantiqueira (Gõni et al. 1962, Jost \& Villwock 1966, Ribeiro et al. 1966), são constituídos por serpentinitos, xistos magnesianos variados, metabasaltos anfibolitos e metagabros, intercalados na sequência metassedimentar, na forma de horizontes concordantes Com a foliação principal. Essas litologias representam derrames máfico-ultramáficos e/ou intrusões ígneas de pequena profundidade, derivados de magmas básicos e ultrabásicos. Intercalações de sedimentitos químicos, representados por meta-cherts, formações ferríferas e rochas com turmalina e grafita, são de ocorrência restrita.

Duas foliações metamórficas principais $\left(\mathrm{S}_{1}\right.$ e $\left.\mathrm{S}_{2}\right)$ foram identificadas para a área, estando as mesmas associadas aos eventos metamórficos regionais $\mathrm{M}_{1}$ (Fácies Anfibolito) e $\mathrm{M}_{2}$ (Fácies Xistos Verdes), respectivamente. O primeiro metamorfismo $\left(\mathrm{M}_{1}\right)$ observado nos anfibólios de rochas metabásicas registra dois episódios de recristalização ( $\sin$ e pós-tectônica), onde as bordas e núcleos deste mineral se reequilibraram na Fácies Anfibolito. Em consequência, as rochas da sequência máfico-ultramáfica sofreram intensa reorganização mineralógica e textural. Apenas algumas texturas e estruturas reliquiares dos tipos amigdaloidal, porfirítica e subofitica (metabasaltos), fragmentos de grão finíssimo (resfriamento rápido) de possíveis bordas de derrames e/ou explosões freato-magmáticas (xistos magnesianos) foram preservadas.

Intrusões graníticas, na forma de lâminas (corpos tabulares), durante $\mathrm{a}_{2}$, datadas pelo método $\mathrm{Rb} / \mathrm{Sr}$ em aproximadamente 660 Ma e agrupadas sob a denominação de Granitóides Sanga do Jobim (Remus 1990), fornecem idades mínimas para o referido complexo. Detalhes sobre a geologia, petrografia e geoquímica dos elementos maiores do Complexo Cambaizinho são tratados num trabalho em separado (Remus \& Hartmann, no prelo).
Neste estudo, são abordados assuntos relacionados à geoguímica dos elementos traços e de terras raras das rochas máficas e ultramáficas. O principal enfoque refere-se à: (a) determinação da afinidade magmática dessas litologias por meio da comparação com sequências máficas e ultramáficas bem preservadas; (b) identificação dos processos predominantes na geração dessas rochas; (c) avaliação da mobilidade relativa dos elementos-traço e terras raras durante os processos de alteração secundária; (d) avaliação dos graus de fusão da fonte (manto) necessários à geração dessas litologias; (e) estimativa da composição do manto (fonte), na região, a partir dos conteúdos de ETR e elementos-traço encontrados nessas rochas; (f) formulação de uma hipótese de origem para essas rochas em relação ao ambiente tectônico.

\section{ELEMENTOS-TRACOO E RAZÕES ENTRE ELEMEN-}

TOS A partir de critérios petrográficos e da geoquímica dos elementos maiores, especialmente $\mathrm{MgO}, \mathrm{CaO}, \mathrm{Al}_{2} \mathrm{O}_{3}$ e $\mathrm{SiO}_{2}$, as rochas da sequência máfico-ultramáfica foram subdivididas nos seguintes grupos: a. rochas portadoras de olivina e/ou serpentina, incluindo serpentinitos e olivinatalco ultramafitos; b. xistos magnesianos com talco; c. clorita e anfibólio xistos, incluindo tremolita-clorita xistos e clorita-anfibólio (tremolita actinolita, hornblenda e antofilita) xistos; d. clorita-hornblenda xistos; e. anfibolitos (metabasaltos); f. metagabros (Remus 1990).

Os serpentinitos e olivina-talco ultramafitos, juntamente com os xistos magnesianos (xistos magnesianos com talco, clorita e anfibólio xistos, clorita-hornblenda xistos), sob o ponto de vista petroquímico podem ser atribuídos à série komatiítica, com base nos conteúdos de $\mathrm{MgO}$, dentre outros aspectos. As rochas com olivina e/ou serpentina são de origem cumulática ou residual de metassomatismo. Os anfibolitos, metabasaltos e os metagabros estão relacionados às suítes toleíticas com alto $\mathrm{MgO}$.

Os resultados das análises químicas para elementos-traço $\mathrm{Cr}, \mathrm{Ni}, \mathrm{V}, \mathrm{Co}, \mathrm{Cu}, \mathrm{Zr}, \mathrm{Rb}, \mathrm{Sr}, \mathrm{Ba}, \mathrm{Y}, \mathrm{Ga}$ e Nb, bem como as razões entre os elementos mais significativos para essas rochas, estão listados nas tabelas 1 a 4 .

O conteúdo dos elementos menores das amostras foram determinados no Laboratório de Análises Químicas de Minerais e Rochas do Instituto de Geociências da UFRGS, sob a responsabilidade da Prof ${ }^{\circ}$ Dione A. Pintaude e do autor sênior. Os teores dos elementos $\mathrm{Cr}, \mathrm{Ni}, \mathrm{V}, \mathrm{Co}, \mathrm{Y}$ e $\mathrm{Zr}$ foram obtidos por Espectrografia Optica de Emissão com chapas espectrográficas Kodak S A-1, com limites de detecção de $50 \mathrm{ppm}$ para o $\mathrm{Zr}$ e $10 \mathrm{ppm}$ para os demais elementos. A determinação do $\mathrm{Zn}$ e $\mathrm{Cu}$ foi efetuada por Espectrometria de Absorção Atómica, modelo Perkin Elmer 703, com limites de detecção de 1 ppm. Os teores de $\mathrm{Rb}, \mathrm{Sr}$ e Ba foram determinados por Espectrometria de Fluorescência de Raios X (Geiger Flex Rigaku), com limites de detecção de 5, 30 e 50 ppm, respectivamente.

Os dados referentes aos elementos-tracos $(\mathrm{Cr}, \mathrm{Ni}, \mathrm{V}, \mathrm{Zn}$, $\mathrm{Cu}, \mathrm{Zr}, \mathrm{Rb}, \mathrm{Sr}, \mathrm{Ba}, \mathrm{Y}, \mathrm{Ga}$ e $\mathrm{Nb}$ ) foram obtidos nos laboratórios da Southampton University, Inglaterra, para as amostras assinaladas com asteriscos nas tabelas respectivas. Estes valores foram determinados pelo segundo autor, utilizando um aparelho Phillips P W -1400 XRF (amostras em pó), com os limites de detecção (em ppm): $\mathrm{Cr}, \mathrm{V}$ e $\mathrm{Cu}=5 ; \mathrm{Ba}=15$; $\mathrm{Zn}, \mathrm{Ni}, \mathrm{Ga}, \mathrm{Rb}, \mathrm{Sr}, \mathrm{Zr}, \mathrm{Y}$ e Nb=2.

\section{Rochas portadoras de olivina e/ou serpentina}

$\mathrm{O}$ controle predominante da olivina no fracionamento dessas rochas está mascarado pelos processos de alteração secundária que mobilizaram o Ni dessas amostras (Fig. 2a). O Cr não mostra correlação aceitável com o MgO (Fig. 2b). Entretanto, se considerados todos os grupos de rochas, notase fraca correlação entre $\mathrm{Cr}$ e o $\mathrm{MgO}$ (coeficiente de correia- 


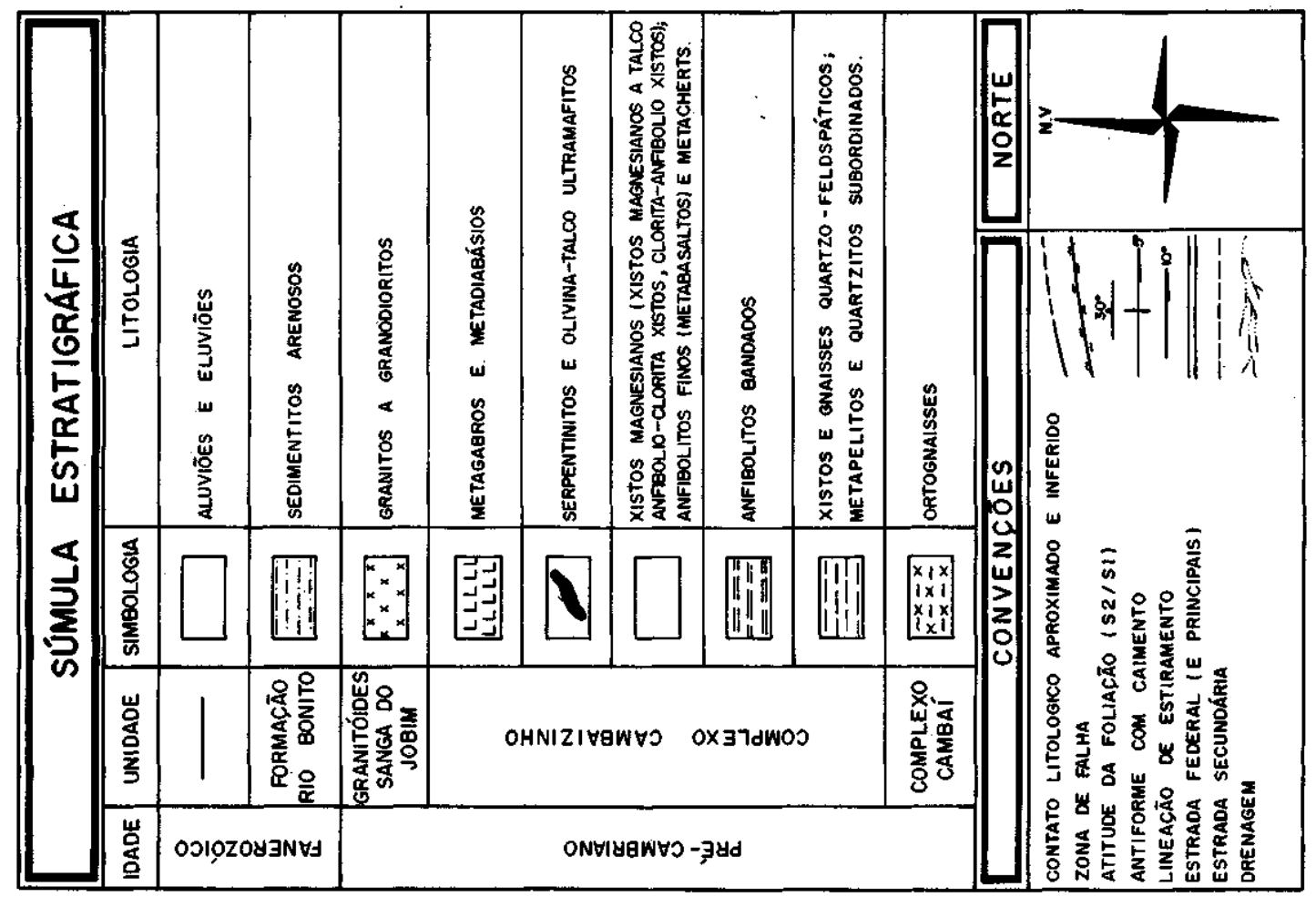

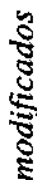

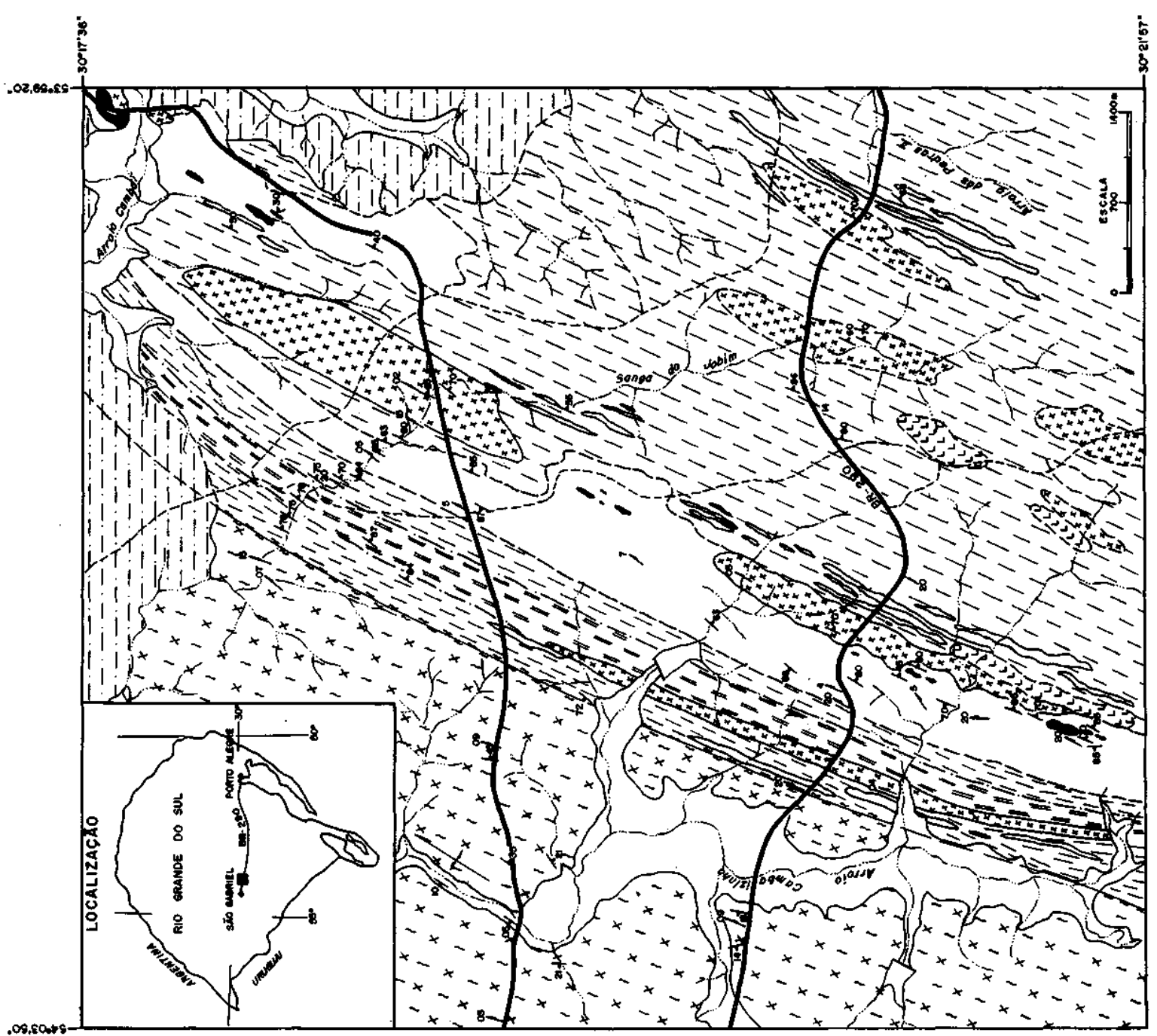


Tabela 1 -Elementos-traço (ppm), razões entre óxidos e elementos dos serpentinitos e olivina-talco ultramafitos da Sequência Máfico-Ultramáfica do Complexo Cambaizinho, São Gabriel - RS

Table 1 - Trace elements (ppm), inter-oxides and element ratios of the sepentinites and olivine-talc ultramafltes of the Mafic Ultramafic Sequence of Cambaizinho Complex, São Gabriel - RS

\begin{tabular}{|c|c|c|c|c|c|c|c|c|c|c|c|}
\hline \multirow[t]{2}{*}{ AMOSTRAS (MR) } & \multicolumn{8}{|c|}{ SERPENTINITOS } & \multicolumn{3}{|c|}{$\begin{array}{l}\text { OLIVINA-TALCO } \\
\text { ULTRAMAFITO }\end{array}$} \\
\hline & $27 \mathrm{D}$ & 73 & $74 E$ & 99E & $99 \mathrm{~K}$ & $99 \mathrm{~N}$ & 134 & 25 & 990 & 101 & $104 \mathrm{H}$ \\
\hline $\mathrm{Cr}$ & 1950 & 2900 & 2800 & 2900 & 2600 & 1800 & 3100 & 3000 & $2091^{*}$ & $1370^{*}$ & 1800 \\
\hline$\overline{\mathrm{Ni}}$ & 1800 & 1500 & 1000 & 2000 & 1800 & 2500 & 1500 & 1800 & $1481 *$ & $1415^{*}$ & 1200 \\
\hline $\mathrm{v}$ & 40 & 40 & 80 & 60 & 50 & 40 & 40 & 80 & $50^{*}$ & $22^{*}$ & 40 \\
\hline $\mathrm{Co}$ & 80 & 170 & 100 & 180 & 110 & 130 & 130 & 250 & 130 & 120 & 80 \\
\hline $\mathrm{Zn}$ & $=$ & $=$ & $=$ & - & - & $=$ & $\overline{-}$ & - & $43^{*}$ & $39 *$ & - \\
\hline $\mathrm{Cu}$ & 5 & 5 & 10 & 5 & 10 & 10 & 10 & 45 & 5* & $0^{*}$ & 10 \\
\hline $\mathrm{Zr}$ & $<50$ & $<50$ & $<50$ & $<50$ & $<50$ & $<50$ & $<50$ & $<50$ & 2* & $3^{*}$ & $<50$ \\
\hline $\mathbf{R b}$ & 6 & $<5$ & $<5$ & $<5$ & $<5$ & $<5$ & $<5$ & $<5$ & $3^{*}$ & $2^{*}$ & $<5$ \\
\hline Sr & $<30$ & $<30$ & $<30$ & $<30$ & $<30$ & $<30$ & $<30$ & $<30$ & $11^{*}$ & $40^{*}$ & $<30$ \\
\hline $\mathrm{Ba}$ & 117 & $<50$ & 62 & $<50$ & $<50$ & $<50$ & $<50$ & 78 & $7 *$ & $8^{*}$ & $<50$ \\
\hline $\mathbf{Y}$ & $<10$ & $<10$ & $<10$ & $<10$ & $<10$ & $<10$ & $<10$ & $<10$ & 6* & $5^{*}$ & $<10$ \\
\hline $\mathrm{Ga}$ & $=$ & $=$ & $=$ & $=$ & - & $=$ & . & - & 3* & $2^{*}$ & - \\
\hline $\mathrm{Nb}$ & - & - & - & - & - & - & - & - & 3* & $2^{*}$ &. \\
\hline
\end{tabular}

RAZOES

\begin{tabular}{|c|c|c|c|c|c|c|c|c|c|c|c|}
\hline $\mathrm{Ca} / \mathrm{Al}_{2} \mathrm{O}_{3}$ & 1,07 & 1,63 & 0,36 & 0,55 & 0,43 & 0,45 & 0,61 & 0,83 & 0,51 & 2,09 & 0,46 \\
\hline $\mathrm{Al}_{2} \mathrm{O}_{3} / \mathrm{TiO}_{2}$ & 15,5 & 13,7 & 22,6 & 21,8 & 18,2 & 20,1 & 18,9 & 10.4 & 43,2 & 16.7 & 17,5 \\
\hline $\mathrm{CaO} / \mathrm{TiO}_{2}$ & 16,7 & 22,3 & 8.13 & 12,0 & 7,83 & 9,00 & 11,4 & 8,6 & 22,2 & 34,9 & 8,00 \\
\hline $\mathrm{TjO}_{2} / \mathrm{P}_{2} \mathrm{O}_{5}$ & 1,3 & 0,75 & 1,00 & 0,56 & 0,75 & 1,00 & 0,90 & 1,54 & 0,83 & 0,78 & 1,00 \\
\hline $\mathrm{FeO}^{*} / \mathrm{FeO}^{*}+\mathrm{MgO}$ & 0,15 & 0,16 & 0.17 & 0,18 & 0,16 & 0,17 & 0,16 & 0,26 & 0,18 & 0,18 & 0,16 \\
\hline $\mathrm{FeO} * / \mathrm{MgO}$ & 0,17 & 0,19 & 0,20 & 0.21 & 0.18 & 0,20 & 0,19 & 0,36 & 0.22 & 0,22 & 0,19 \\
\hline $\mathrm{FeO} / \mathrm{Fe}_{2} \mathrm{O}_{3}$ & 0,43 & 0,10 & 0,29 & 0,09 & 0,11 & 0,36 & 0,62 & 0,29 & 2,07 & 0,74 & 1,82 \\
\hline $\mathrm{Si} / \mathrm{Ti}$ & 288 & 589 & 467 & 719 & 646 & 449 & 421 & 178 & 865 & 614 & 518 \\
\hline $\mathrm{Al} / \mathrm{Ti}$ & 13,7 & 12,1 & 20 & 19,3 & 16,1 & 17,8 & 16,7 & 9,18 & 38,1 & 14,8 & 15,5 \\
\hline $\mathrm{Fe} / \mathrm{Ti}$ & 67 & 177 & 130 & 231 & 158 & 135 & 111 & 82 & 186 & 132 & 116 \\
\hline $\mathrm{Mg} / \mathrm{Ti}$ & 305 & 717 & 508 & 838 & 669 & 526 & 443 & 180 & 666 & 474 & 463 \\
\hline $\mathrm{Ca} / \mathrm{Ti}$ & 19,9 & 26,6 & 9,69 & 14,3 & 9,34 & 10,7 & 13,6 & 10,3 & 26.5 & 41,6 & 9,54 \\
\hline $\mathrm{Ti} / \mathrm{Nb}$ & - & - & - & - & - & - & - & - & 100 & 210 & - \\
\hline $\mathrm{Ti} / \mathrm{Zr}$ & - & - & - & - & . & - & - & - & 150 & 140 & - \\
\hline $\mathrm{Ti} / \mathrm{Y}^{\prime}$ & - & - & - & - & - & - & - &. & 50 & 84 &. \\
\hline $\mathrm{Zr} / \mathrm{Nb}$ & - & $=$ & - &. & $=$ & - & - & - & 0,66 & 1,5 & - \\
\hline $\mathrm{Zr} / \mathrm{Y}$ & - & - & - & - & - & - & - & - & 0,33 & 0,6 & - \\
\hline
\end{tabular}

(*) Dados obtidos na Southampton University - Inglaterra

ção $=0,72$ ), indicando que no fracionamento houve participação de uma fase rica em $\mathrm{Cr}$ (cromita, piroxênio), além de olivina. Da mesma forma, para o V (Fig. 2c), quando considerado todo o conjunto de amostras, existe um trend de correlação negativa (coeficiente de correlação $=0,73$ ) que intercepta o eixo x a cerca de $40-45 \%$ de $\mathrm{MgO}$, o que está de acordo com as observações precedentes; ou seja, o fracionamento da olivina é um dos controladores da composição dessas rochas.

A suposta natureza cumulática e/ou residual metassomática dessas rochas é também demonstrada pela tendência de as amostras desse tipo litológico se locarem em grupos composicionais restritos e isolados do restante da sequência máfico-ultramáfica, como pode ser observa- do nos diagramas $\mathrm{Al}_{2} \mathrm{O}_{3} / \mathrm{TiO}_{2}, \mathrm{TiO}_{2} / \mathrm{CaO}, \mathrm{TiO}_{2} / \mathrm{P}_{2} \mathrm{O}_{5}$ (Fig. $3 a, b, c)$.

A abundância e as razões dos elementos incompatíveis e refratários dessas rochas (Tab. 1) foram substancialmente modificadas pelos processos de fracionamento/acumulação e de alteração secundária (metassomática). Desta forma, não registram mais aqueles níveis existentes no líquido primário que lhes deu origem. As características geoquímicas ainda preservadas indicam que os serpentinitos e os olivina-talco ultramafitos se assemelham a cumulados komatííticos e a cumulados de ofiolitos. As ocorrências de campo, na forma de lentes alongadas, e a associação com xistos magnesianos de afinidade komatiítica indicam que esse grupo litológico pode corresponder a cumulados de base de derrames ou de 

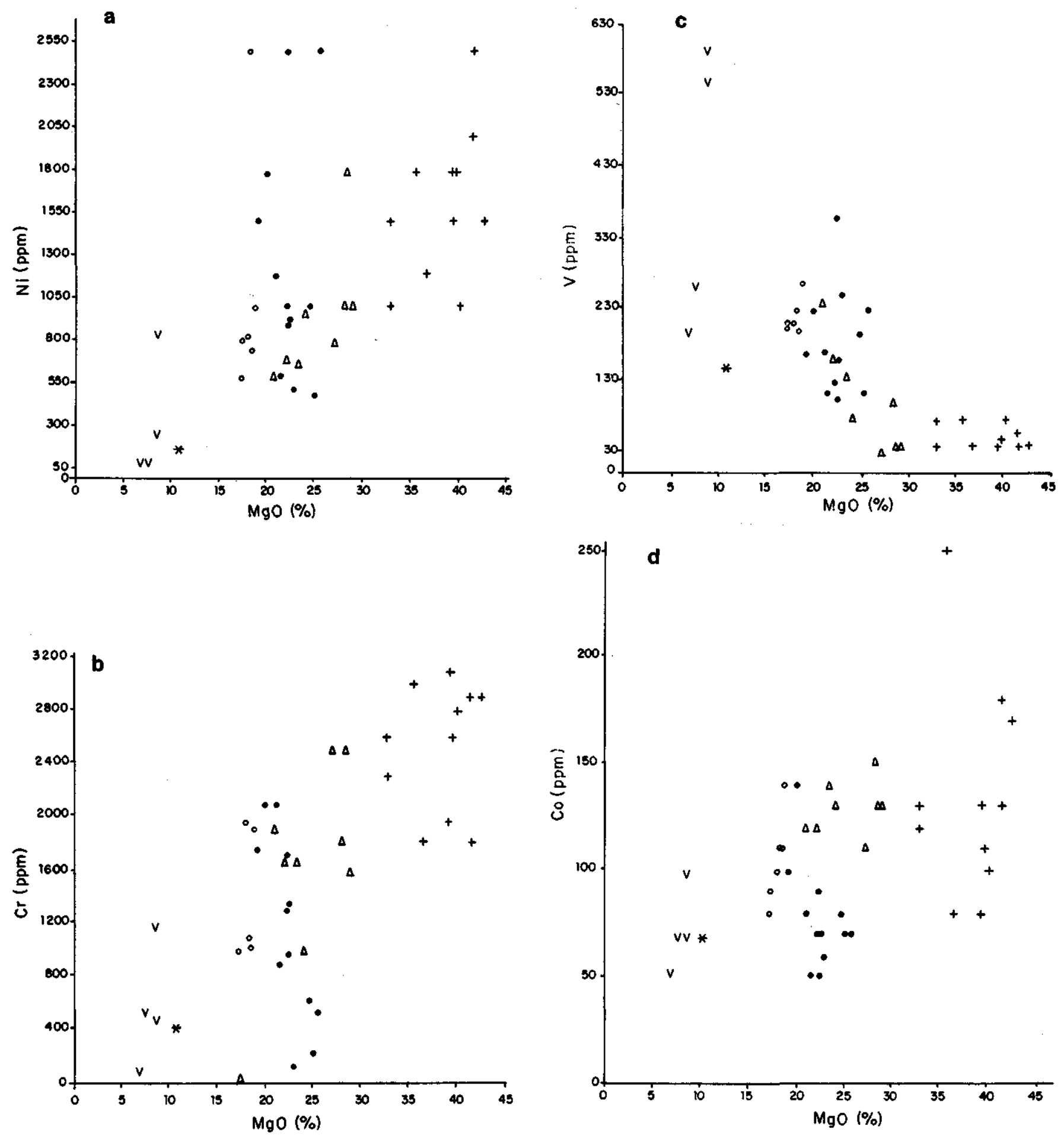

Figura 2 - Diagrama de variação dos elementos (ppm) em relação ao $\mathrm{MgO}$ (\% em peso): (a) $\mathrm{Ni}$ x $\mathrm{MgO}$ e (b) $\mathrm{Cr}$ x $\mathrm{MgO}$, com fraca correlação positiva e pequena dispersão de pontos, (c) Vx MgO exibindo correlação negativa e (d) Co $x \mathrm{MgO}$ com distribuição de pontos menos regulares. Simbologia para as figuras 2, 3 e 4: Serpentinitos e olivina-talco ultramafitos (cruzes); xistos magnesianos com talco (triângulo); clorita e anfibólio (tremolita, actinolita, hornblenda ou antofilita) xistos (círculo fechado); clorita-hornblenda xistos (círculo aberto); anfibolitos (vê); meta-gabros (asterisco) e clorítito (xis) Figure 2 - Variation diagrams of trace elements (ppm) versu $\mathrm{MgO}$ (weight percent): (a) $\mathrm{Ni}$ x $\mathrm{MgO}$ and (b) $\mathrm{Cr}$ x $\mathrm{MgO}$, displaying positive correlation and small dispersion of points; (c) V x MgO showing negative correlation and (d) $\mathrm{Co}$ x $\mathrm{MgO}$ with less regular distribution of points. Simbology, for figures 2 , 3 and 4: Serpentinites and olivine-talc ultramafites (crosses); magnesian schists with tale (triangles), chlorite and amphibole (tremolite, actinolite, hornblende and anthophyllite) schists (closed circle); chlorite-hornblende schists (open circle); amphibolites (v); metagabbro $\left({ }^{*}\right)$ and chloritite (x)

sills komatíticòs ou estão relacionados, ainda, a intrusões ígneas rasas de composição komatítica, transformadas por processos metamórficos/metassomáticos relatados anteriormente.
Xistos magnesianos com talco Do mesmo modo que para os outros grupos mineralógicos individuais, notase uma tendência de ocorrerem variações significativas nos teores de $\mathrm{Ni}, \mathrm{Cr}$ e $\mathrm{Co}$ com pequenas variações nos teores de 
Tabela 2 - Elementos-traço (ppm), razões entre óxidos e elementos dos xistos magnesianos com talco da Sequência MáficoUltramáfica do Complexo Cambaizinho, São Gabriel - RS

Table 2 - Trace elements (ppm) inter-oxides and element ratios of the magnesian schists with tale of the Mafic-Ultramafic Sequence of Cambaizinho Complex, São Gabriel - RS

\begin{tabular}{|c|c|c|c|c|c|c|c|c|}
\hline \multirow{2}{*}{$\begin{array}{l}\text { Amostras } \\
\text { (MR) }\end{array}$} & \multicolumn{8}{|c|}{ Xistos Magnesianos 'Talco } \\
\hline & 60 & 22 & $\mathbf{8 4 F}$ & 105 & 106 & 102 & $104 \mathrm{E}$ & $104 \mathrm{~J}$ \\
\hline $\mathrm{Cr}$ & 1800 & 2500 & 1600 & 1650 & 2500 & $999^{*}$ & 1650 & 1900 \\
\hline $\mathrm{Ni}$ & 1000 & 800 & 1000 & 680 & 1800 & $971^{*}$ & 700 & 600 \\
\hline $\mathbf{V}$ & 100 & 30 & 40 & 140 & 40 & $80^{*}$ & 160 & 240 \\
\hline Co & 150 & 110 & 130 & 140 & 130 & 130 & 120 & 120 \\
\hline $\mathrm{Zn}$ & $=$ & - & $=$ & $\cdot$ & $=$ & $66^{*}$ & - & - \\
\hline $\mathrm{Cu}$ & 10 & 5 & 5 & 5 & 5 & $0^{*}$ & 5 & 5 \\
\hline $\mathrm{Zr}$ & $<50$ & $<50$ & $<50$ & $<50$ & $<50$ & $45^{*}$ & $<50$ & $<50$ \\
\hline $\mathbf{R b}$ & $<5$ & $<5$ & $<5$ & $<5$ & $<5$ & 3* & $<5$ & $<5$ \\
\hline $\mathrm{Sr}$ & 61 & 59 & $<30$ & 38 & $<30$ & $21^{*}$ & $<30$ & $<30$ \\
\hline $\mathrm{Ba}$ & 130 & 63 & $<50$ & $<50$ & 99 & $10^{*}$ & $<50$ & $<50$ \\
\hline $\mathrm{Y}$ & $<10$ & $<10$ & $<10$ & $<10$ & $<10$ & $17^{*}$ & $<10$ & 40 \\
\hline $\mathrm{Ga}$ & $=$ &. & $=$ & $=$ &. & $6^{*}$ & $=$ & 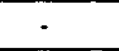 \\
\hline $\mathrm{Nb}$ & - & 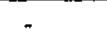 & $=$ &. & - & $8^{*}$ & $=$ & . \\
\hline
\end{tabular}

\begin{tabular}{|c|c|c|c|c|c|c|c|c|}
\hline $\mathrm{Ca} / \mathrm{Al}_{2} \mathrm{O}_{3}$ & 0,63 & 1,99 & 0,35 & 2,93 & 0,35 & 1,30 & 3,51 & 2,12 \\
\hline $\mathrm{Al}_{2} \mathrm{O} / \mathrm{TiO}_{2}$ & 11,7 & 31,8 & 25,9 & 4,94 & 22,2 & 9,24 & 10,9 & 6,58 \\
\hline $\mathrm{CaO} / \mathrm{TiO}_{2}$ & 7,39 & 63,5 & 9,00 & 14,5 & 7,79 & 12,1 & 38,2 & 13.9 \\
\hline $\mathrm{TiO}_{2} / \mathrm{P}_{2} \mathrm{O}_{3}$ & 2,93 & 0,60 & 0,73 & 4,13 & 2,38 & 4,21 & 1,45 & 4,75 \\
\hline $\mathrm{FeO}^{*} / \mathrm{FeO}^{*}+\mathrm{MgO}$ & 0,21 & 0,18 & 0,17 & 0,21 & 0,18 & 0,25 & 0,23 & 0,26 \\
\hline $\mathrm{FeO} / \mathrm{MgO}$ & 0,26 & 0,22 & 0,20 & 0,26 & 0,21 & 0.22 & 0,30 & 0,35 \\
\hline $\mathrm{FeO} / \mathrm{Fe}_{2} \mathrm{O}_{3}$ & 3,40 & 3,90 & 4,96 & 5,23 & 3,81 & 5,82 & 5,25 & 14,68 \\
\hline $\mathrm{Si} / \mathrm{Ti}$ & 105 & 780 & 601 & 71 & 241 & 71 & 149 & 56 \\
\hline $\mathrm{Al} / \mathrm{Ti}$ & 10,3 & 28 & 23 & $\overline{4,4}$ & 19,6 & 8,2 & 9,6 & 5,8 \\
\hline $\mathrm{Fe} / \mathrm{Ti}$ & 23,6 & 132 & 93 & 12,9 & 41,5 & 17,3 & 29,7 & 12,5 \\
\hline $\mathrm{Mg} / \mathrm{Ti}$ & 69 & 457 & 366 & 38.1 & 151 & 41 & 77 & 28 \\
\hline $\mathrm{Ca} / \mathrm{Ti}$ & 8,8 & 75,7 & 11 & 17,2 & 9,3 & 14,4 & 46 & 16,6 \\
\hline $\mathrm{Ti} / \mathrm{Nb}$ & - & - & - & - & - & 442 & . & - \\
\hline $\mathrm{T} \mathrm{i} / \mathrm{Zr}$ & - & - & . & - & - & 78 & . &. \\
\hline $\mathrm{Ti} / \mathrm{Y}$ & - & - & - & . & - & 208 & - & 114 \\
\hline$\overline{\mathrm{Z} r} / \mathrm{Nb}$ & - & - & - & - & - & 5,6 & 2 & . \\
\hline $\mathrm{ZT} / \mathrm{Y}$ & $=$ & - & $=$ & $=$ & $=$ & 2,6 & - & 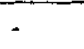 \\
\hline
\end{tabular}

(*) Dados obtidos na Southampton University - Inglaterra

MgO (Figs. 2a, b e d). O vanádio desses xistos apresenta discreta correlação negativa, com este último óxido no diagrama respectivo (Fig. 2c). Essas relações, especialmente $\mathrm{V} \times \mathrm{MgO}$ e $\mathrm{Cr}$ x MgO, acompanham os trends de fracionamento ígneo dos demais ultramafltos, quando se considera todo o conjunto de grupos mineralógicos.

As características geoquímicas primárias dos xistos magnesianos com talco apresentam sensíveis modificações nos conteúdos dos elementos maiores e traços por sua origem estar relacionada a processos metamórficos-metassomáticos, que ocasionaram a redistribuição dos vários elementos químicos $\left(\mathrm{SiO}_{2}\right.$, álcalis, $\left.\mathrm{TiO}_{2}\right)$. Em consequência, as razões dos elementos maiores $\mathrm{CaO} / \mathrm{Al}_{2} \mathrm{O}_{3} ; \mathrm{Al}_{2} \mathrm{O} / \mathrm{TiO}_{2} ; \mathrm{CaO} / \mathrm{TiO}_{2} ; \quad \mathrm{TiO}_{2} /$ $\mathrm{P}_{2} \mathrm{O}_{5}$ e dos vários elementos-traço listados na tabela 2 são bastante variáveis e inconsistentes, tornando-se pouco con- fiáveis para serem utilizadas como indicadoras dos processos petrogenéticos geradores deste grupo de rochas.

Mesmo assim, algumas relações originais preservadas, como $\mathrm{FeO} * / \mathrm{FeO}^{*}+\mathrm{MgO}, \mathrm{FeO}^{*} / \mathrm{MgO}$, entre outras, e as boas correlações para $\mathrm{V}$ x $\mathrm{MgO}$ permitem identificar 0 piroxênio e, subordinadamente, a olivina como as supostas fases minerais responsáveis pelas suas variações composicionais. Além disso, algumas amostras (MR-60 e MR102) possuem determinadas relações $\mathrm{CaO} / \mathrm{Al}_{2} \mathrm{O}_{3}, \mathrm{Al}_{2} \mathrm{O}_{3} /$ $\mathrm{TiO}_{2}$ e $\mathrm{CaO} / \mathrm{TiO}_{2}$ parcialmente preservadas e com valores próximos aos encontrados em rochas komatiíticas (Nesbitt \& Sun 1976, Smith \& Erlank 1982).

Clorita e anfibólio xistos Neste agrupamento de rochas, não existe correlação aceitável para o Ni, Cr, V e Co. 
Tabela 3-Elementos-traço (ppm), razões entre óxidos e elementos dos clorita e anfibólio xistos e clorítito (MR-125A) da Sequência Máfico-Ultramáfica do Complexo Cambaizinho, São Gabriel - RS

Table 3 - Trace elements (ppm) inter-oxides and elements ratios of the chlorite and amphibole schists and chloritites (MR-125A) of the Mafic-Ultramafic Sequence of Cambaizinho Complex, São Gabriel - RS

\begin{tabular}{|c|c|c|c|c|c|c|c|c|c|c|c|c|c|}
\hline \multirow{2}{*}{$\begin{array}{l}\text { Amostras } \\
\text { (MR) }\end{array}$} & \multicolumn{10}{|c|}{ CLORITA-ANFIBÓLIO XISTOS } & \multicolumn{3}{|c|}{$\begin{array}{c}\text { TREMOLITA-CLORITA } \\
\text { XISTOS }\end{array}$} \\
\hline & 145 & 147 & 148 & 149 & $62 \mathrm{~b}$ & $63 \mathrm{I}$ & $63 \mathrm{~N}$ & 630 & $62 \mathrm{H}$ & $62 \mathrm{~J}$ & $63 \mathrm{~J}$ & $63 \mathrm{~K}$ & $125 \mathrm{~A}$ \\
\hline $\mathrm{Cr}$ & 1300 & 1350 & 1750 & 2100 & $237^{*}$ & 2100 & $976^{*}$ & $902 *$ & $142^{*}$ & 1700 & 520 & 630 & 700 \\
\hline $\mathrm{Ni}$ & 1000 & 920 & 1500 & 1200 & $482^{*}$ & 1800 & $934^{*}$ & $606^{*}$ & $513^{*}$ & 2500 & 2500 & 1000 & 500 \\
\hline$\vec{v}$ & 130 & 160 & 170 & 170 & $116^{*}$ & 230 & $108^{*}$ & $115^{*}$ & $255^{*}$ & 360 & 230 & 200 & 640 \\
\hline $\mathrm{Co}$ & 70 & 50 & 100 & 80 & 70 & 140 & 70 & 50 & 60 & 90 & 70 & 80 & 90 \\
\hline $\mathrm{Zn}_{\mathbf{n}}$ & - & - & - & $-\cdot$ & $63^{*}$ & - & $90^{*}$ & $67^{*}$ & $101^{*}$ & & $\cdot$ & $\cdot$ & . \\
\hline $\mathrm{Cu}$ & 15 & 25 & 25 & $35^{*}$ & $0^{*}$ & 55 & $1 *$ & $19 *$ & $0^{*}$ & 80 & 5 & 15 & 115 \\
\hline $\mathbf{z}$ & 55 & $<50$ & $<50$ & $\$ 0$ & 91* & $<50$ & 93* & $50^{*}$ & $188^{*}$ & 65 & 60 & 75 & 170 \\
\hline $\mathbf{R b}$ & $<5$ & $<5$ & $<5$ & $<5$ & 3* & $<5$ & $2 *$ & $2^{*}$ & $3^{*}$ & $<5$ & $<5$ & $<5$ & $<5$ \\
\hline $\mathrm{Sr}$ & $<30$ & 34 & $<30$ & $<30$ & 24 & 32 & $12^{*}$ & $13^{*}$ & $15^{*}$ & $<30$ & $<30$ & $<30$ & 97 \\
\hline $\mathrm{Ba}$ & $<50$ & & $<50$ & $<50$ & $19^{*}$ & $<50$ & $16^{*}$ & $7 *$ & $21^{*}$ & $<50$ & $<50$ & $<50$ & 270 \\
\hline $\mathbf{Y}$ & 20 & 20 & 20 & 20 & $22^{*}$ & 30 & $22^{*}$ & $22^{*}$ & $31 *$ & 40 & 40 & 30 & 70 \\
\hline Ga & : & - & $=$ & - & $10^{*}$ & - & $12^{*}$ & $11^{*}$ & $18 *$ & - & : & . & . \\
\hline $\mathrm{Nb}$ & . & $=$ & . & $=$ & $10^{*}$ & $=$ & $8 *$ & $6^{*}$ & $21 *$ & - & . & . & . \\
\hline
\end{tabular}

RAZÕES

\begin{tabular}{|c|c|c|c|c|c|c|c|c|c|c|c|c|c|}
\hline $\mathrm{Ca} / \mathrm{Al}_{2} \mathrm{O}_{3}$ & 0,81 & 1,07 & 0.86 & 0,93 & 1,05 & 1,26 & 1,00 & 1,12 & 0,37 & 0,68 & 0.57 & 0,66 & 0.05 \\
\hline $\mathrm{Al}_{2} \mathrm{O} / \mathrm{TiO}_{2}$ & 9,64 & 11,1 & $\$ 1,2$ & 10,5 & 8,59 & 5,93 & 10,8 & 14,8 & 4,58 & 5,92 & 13,0 & 11,0 & 2,75 \\
\hline $\mathrm{CaO} / \mathrm{TiO}_{2}$ & 7,81 & 11,9 & 9,57 & 9.70 & 9,00 & 7,46 & 10,8 & 16,6 & 1,71 & 4,02 & 7,36 & 7,26 & 0,12 \\
\hline $\mathrm{TO} \mathrm{N}_{2} \mathrm{P}_{2} \mathrm{O}_{5}$ & 8,75 & 5,62 & 7,33 & 7,17 & 3,25 & 5.77 & 2,86 & 3,53 & 8.30 & 6.79 & 3,67 & 5,16 & 14,4 \\
\hline $\begin{array}{l}\mathrm{FeO} * / \mathrm{FeO}^{*}+ \\
\mathrm{MgO}\end{array}$ & 0,31 & 0,3 & 0,35 & 0,31 & 0,27 & 0,36 & 0,26 & 0,28 & 0,34 & 0,37 & $\mathbf{0 , 3 0}$ & 0,29 & 0,38 \\
\hline $\mathrm{FeO} * \mathrm{MgO}$ & 0,46 & 0,44 & 0.53 & 0,46 & 0,33 & 0,57 & 0,35 & 0.39 & 0,51 & 0,59 & 0,42 & 0,40 & 0,62 \\
\hline $\mathrm{FeO} / \mathrm{Fe}_{2} \mathrm{O}_{3}$ & 5,34 & 6,83 & 6,34 & 9,31 & 2,85 & 2,50 & 3,77 & 2,61 & 3,61 & 2,53 & 2,75 & 2,95 & 1,58 \\
\hline $\mathrm{S} \mathrm{i} / \mathrm{Ti}$ & 34,5 & 52,1 & 44,5 & 45,3 & 41,0 & 30,0 & 48,5 & 63,3 & 10,5 & 17,1 & 38,1 & 36,1 & 3,41 \\
\hline $\mathrm{Al} / \mathrm{Ti}$ & 8,51 & 9,78 & 9,85 & 9,24 & 7,59 & 5,23 & 9,50 & 13,1 & 4,04 & 5,22 & 11,5 & 9.72 & 2,43 \\
\hline $\mathrm{Fe} / \mathrm{Ti}$ & 13 & 17,0 & 15,0 & 14,4 & 11,7 & 11,6 & 12,9 & 18,3 & 4,97 & 8,94 & 16,0 & 13,0 & 3,28 \\
\hline $\mathrm{Mg} / \mathrm{Ti}$ & 21,3 & 31,1 & 22,0 & 24,6 & 27,9 & 15,9 & 28,4 & 36,2 & 7,53 & 11,9 & 29,4 & 25,4 & 4,11 \\
\hline $\mathrm{Ca} / \mathrm{Ti}$ & 9,31 & 14,2 & 11,4 & 11,6 & 10,7 & 8,9 & 12,9 & 19,8 & 2,03 & 4,79 & 8.78 & 8,65 & 0.15 \\
\hline $\mathrm{Ti} / \mathrm{Nb}$ & $\therefore$ & . & - & - & 545 & - & 600 & 600 & 876 & - & - & - & - \\
\hline $\mathrm{Ti} / \mathrm{Zr}$ & 114 & - & - & - & 60 & - & 88 & 78 & 52 & 175 & 88 & 78 & 233 \\
\hline$T / Y Y$ & 314 & 219 & 263 & 258 & 248 & 253 & 218 & 164 & 594 & 285 & 132 & 196 & 566 \\
\hline $\mathrm{Zr} / \mathrm{Nb}$ & - & - & - & . & 9,1 & - & 11,6 & 8,3 & 9,0 & $=$ & - & - & - \\
\hline $\mathrm{Zr} / \mathrm{Y}$ & 2,75 & . & - & - & 4,14 &. & 4,2 & 2,3 & 6.1 & 1.63 & 1,5 & 2,5 & 2,43 \\
\hline
\end{tabular}

(*) Dados obtidos na Southampton University - Inglaterra

Contudo, ao considerar-se todo o conjunto de amostras, nota-se trends, segundo faixas aproximadamente lineares, definindo correlações fracas para o Ni e o $\mathrm{Cr}$ (Figs. 2a e b). Para o V (Fig. 2c), o conjunto de pontos posiciona-se segundo uma faixa encurvada, sugerindo correlação exponencial. Nessas rochas, algumas amostras apresentam razões entre elementos maiores e traços (Tab. 2) consistentes e, em alguns casos, aproximam-se dos valores existentes em suítes arqueanas (Nesbitt \& Sun 1976, Smith \& Erlank 1982) e, mais raramente, daqueles dos condritos (Wänke et al 1974). Eliminando-se as amostras com valores extremos, foram selecionados os dados referentes às amostras de uma cama- da (derrame?) de clorita-tremolita xisto denominada de camada A (amostra MR-145, MR-147, MR-148 e MR-149), utilizadas como indicadores dos processos petrogenéticos maiores que participaram na geração dessas rochas.

Estes xistos apresentam razões entre óxidos e elementos $\left(\mathrm{CaO} / \mathrm{Al}_{2} \mathrm{O}_{3} ; \mathrm{Al}_{2} \mathrm{O}_{3} / \mathrm{TiO}_{2} ; \mathrm{CaO} / \mathrm{TiO}_{2} ; \mathrm{TiO}_{2} / \mathrm{P}_{2} \mathrm{O}_{5} ; \mathrm{Si} / \mathrm{Ti} ; \mathrm{Mg} /\right.$ $\mathrm{Ti}$; Ti/Y), listados na tabela 3 , dentro de um campo relativamente restrito de valores e que se aproximam aos encontrados em komatiitos, basaltos komatí́ticos arqueanos e a MORBs, relativamente enriquecidos em elementos incompatíveis (Sun \& Nesbitt 1978, Nesbitt et al 1979, Sun et al 1979, Sun 1984). 
Tabela 4 - Elementos-traço (ppm), razões entre óxidos e elementos dos clorita-hornblenda xistos, anfibolitos e metagabro da Sequência Máfico-Ultramáfica do Complexo Cambaizinho, São Gabriel - RS

Table 4 - Trace elements (ppm) inter-oxides and element ratios of the chlorite-hornblende schists, amphibolite and metagabbro of the Mafic-Ultramafic Sequence of Cambaizinho Complex, São Gabriel - RS

\begin{tabular}{|c|c|c|c|c|c|c|c|c|c|c|c|}
\hline \multirow{2}{*}{ Amostras (MR) } & \multicolumn{7}{|c|}{ CLORITA-HORNBLENDA XISTOS } & \multicolumn{2}{|c|}{ ANFTBOLITOS } & \multicolumn{2}{|c|}{ METAGABRO } \\
\hline & 155* & $156^{*}$ & $157^{*}$ & 158* & $62 \mathrm{~K}$ & $82^{*}$ & $62 \mathrm{E}$ & $111^{*}$ & $79 \mathrm{~A}$ & 151 & $83 C^{*}$ \\
\hline $\mathrm{Cr}$ & 991 & 1324 & 1947 & 1016 & 1100 & 1900 & 500 & 116 & 1200 & 560 & 437 \\
\hline $\mathrm{Ni}$ & 577 & 805 & 820 & 750 & 2500 & 1000 & 840 & 83 & 280 & 100 & 183 \\
\hline $\mathrm{v}$ & 211 & 206 & 212 & 202 & 230 & 270 & 600 & 201 & 560 & 270 & 153 \\
\hline Co & 80 & 90 & 100 & 110 & 110 & 140 & 70 & 50 & 100 & 70 & 70 \\
\hline Zn & 88 & 89 & 96 & 82 & $\therefore$ & $\therefore$ & - & 85 & - & . & 55 \\
\hline $\mathrm{Cu}$ & 84 & 33 & 54 & 56 & 10 & 10 & 45 & 51 & 65 & 50 & 44 \\
\hline $\mathrm{Zr}_{\mathrm{r}}$ & 80 & 79 & 96 & 79 & $<50$ & $<50$ & 110 & 171 & 75 & 75 & 65 \\
\hline $\mathbf{R b}$ & 1 & 2 & 2 & 2 & $<5$ & $<5$ & $<5$ & 10 & 10 & 20 & 17 \\
\hline Sr & 28 & 26 & 30 & 29 & 40 & 54 & 265 & 484 & 175 & 185 & 273 \\
\hline $\mathbf{B a}$ & 42 & 22 & 100 & 9 & $<50$ & $<50$ & 80 & 109 & $<50$ & 270 & 119 \\
\hline $\mathbf{Y}$ & 21 & 20 & 25 & 20 & 30 & 40 & 50 & 29 & 50 & 40 & 18 \\
\hline Ga & 15 & 14 & 15 & 12 & - & - & - & 20 & - & - & 14 \\
\hline $\mathrm{Nb}$ & 10 & 10 & 12 & 11 & - & $\cdot$ & - & 6 & - & - & 3 \\
\hline \multicolumn{12}{|c|}{ RAZÓES } \\
\hline $\mathrm{Ca} / \mathrm{Al}_{2} \mathrm{O}_{3}$ & 0,95 & 1,04 & 0,84 & 1,11 & 1,51 & 1,10 & 0,74 & 0,55 & 0,77 & 0,90 & 0,68 \\
\hline $\mathrm{Al}_{2} \mathrm{O}_{2} \mathrm{TiO}_{7}$ & 6,81 & 6,45 & 7,19 & 6,18 & 9,96 & 7,14 & 6,42 & 10,6 & 7,64 & 15,3 & 21,3 \\
\hline $\mathrm{CaO} / \mathrm{TiO}_{2}$ & 6,48 & 6,72 & 6.01 & 6,86 & 15,1 & 7,88 & 4,75 & 5,87 & 5,91 & 13,7 & 14,7 \\
\hline $\mathrm{TiO}_{2} / \mathrm{P}_{2} \mathrm{O}_{3}$ & 10 & 9,50 & 9.69 & 10,9 & 4,17 & 6,32 & 7.52 & 5,56 & 8,46 & 4.67 & 4,69 \\
\hline $\mathrm{FeO} / / \mathrm{FeO}^{*}+\mathrm{MgO}$ & 0,41 & 0,40 & 0,40 & 0,34 & 0,34 & 0,35 & 0,55 & 0,55 & 0.55 & 0,58 & 0,42 \\
\hline $\mathrm{FeO} * / \mathrm{MgO}$ & 0,70 & 0,67 & 0,67 & 0.51 & 0.51 & 0,53 & 1.20 & 1.23 & 1,21 & 1,42 & 0.72 \\
\hline $\mathrm{FeO} / \mathrm{Fe}_{2} \mathrm{O}_{3}$ & 3,23 & 2,98 & 3,25 & 38,25 & 2,71 & 7,83 & 3,18 & 3,27 & 8.72 & 3,42 & 4,11 \\
\hline $\mathrm{Si} / \mathrm{Ti}$ & 24,8 & 24,6 & 23,1 & 25,3 & 52,7 & 32,8 & 19,8 & 27,9 & 20,8 & 37,5 & 51,5 \\
\hline $\mathrm{Al} / \mathrm{Ti}$ & 6,01 & 5,69 & 6,35 & 5,45 & 8.79 & 6,31 & 5,67 & 9,34 & 6.75 & 13,5 & 18,8 \\
\hline $\mathrm{Fe} / \mathrm{Ti}$ & 10,3 & 9,93 & 10,1 & 8,01 & 16,1 & 10,9 & 6,67 & 7,43 & 7,31 & 14,4 & 13.7 \\
\hline $\mathrm{Mg} / \mathrm{Ti}$ & 11,5 & 11,5 & 11,7 & 12,2 & 24,5 & 15,7 & 4,30 & 4,67 & 4,70 & 7,88 & 14.7 \\
\hline $\mathrm{Ca} / \mathrm{Ti}$ & 7,73 & 8,01 & 7,17 & 8,18 & 17,9 & 9,40 & 5,67 & 6,99 & 7,04 & 16,3 & 17,5 \\
\hline $\mathrm{T} / \mathrm{Nb}$ & 899 & 911 & 774 & 828 & - & - & - & 1499 & - & - & 1499 \\
\hline $\mathrm{Ti} / \mathrm{Zr}$ & 112 & 115 & 97 & 115 & - & - & 111 & 53 & 149 & 78 & 69 \\
\hline $\mathrm{Ti} / \mathrm{Y}$ & 428 & 456 & 372 & 456 & 150 & 180 & 243 & 310 & 223 & 147 & 250 \\
\hline $\mathrm{Zr} / \mathrm{Nb}$ & 8 & 7,9 & 8 & 7,2 & - & - & - & 28.5 & - & - & 21,7 \\
\hline $\mathrm{Zr} / \mathrm{Y}$ & 3,8 & 3,95 & 3,84 & 3,95 & - & - & 2,2 & 5,9 & 1,5 & 1,9 & $\mathbf{3 , 6}$ \\
\hline
\end{tabular}

(*) Dados obtidos na Southampton University - Inglaterra

No gráfico $\mathrm{Al}_{2} \mathrm{O}_{3} / \mathrm{TiO}_{2}$ da figura $3 \mathrm{a}$, essas rochas apresentam correlação positiva razoável com trena aproximadamente linear, sendo possível definir razões em torno de 11 para tais óxidos. Suprimindo as amostras mais alteradas (MR-62H e MR-62J), observa-se um fraco trena de correlação positiva no diagrama $\mathrm{CaO} / \mathrm{TiO}_{2}$ (Fig. 3b), definindo razões próximas a 10 ou menores para estes óxidos. Valores similares para razões $\mathrm{Al}_{2} \mathrm{O}_{3} / \mathrm{TiO}_{2}(\sim 10)$ são encontrados nos komatiitos e basaltos komatiíticos do Barberton (Smith \& Erlank 1982) e em basaltos magnesianos do arqueano de Minnesota (Schulz 1982). Além disso, komatiitos com elevados teores de $\mathrm{TiO}_{2}$ ocorrem no greenstone belt de Karasjok, na Noruega (Barnes \& Often 1990).
Os condritos possuem relações $\mathrm{Al}_{2} \mathrm{O}_{3} / \mathrm{TiO}_{2}=20,4$ e $\mathrm{CaO} /$ $\mathrm{TiO}_{2}=17$ (Wänke et al. 1974). Assim, os valores inferiores encontrados nas amostras da camada $\mathrm{A}$ indicam que, provavelmente, o $\mathrm{Al}$ e o $\mathrm{Ca}$ foram menos incompatíveis que o $\mathrm{Ti}$ nestes níveis de fusão (Nesbitt \& Sun 1976). Os valores elevados de $\mathrm{TiO}_{2}$ se originaram pelo enriquecimento relativo nos primeiros líquidos, gerados durante a fusão sequencial (Nesbitt et al. 1979) ou refletem a abundância encontrada num manto enriquecido (Ludden \& Gelinas 1982, Sun 1984).

As razões $\mathrm{CaO} / \mathrm{TiO}_{2}$ e $\mathrm{Al}_{2} \mathrm{O}_{3} / \mathrm{TiO}_{2}$ definem um trena de correlação positiva no gráfico $\mathrm{CaO} / \mathrm{TiO}_{2}: \mathrm{Al}_{2} \mathrm{O}_{3} / \mathrm{TiO}_{2}$ (Fig. $3 \mathrm{~d})$. As amostras se posicionam na região de baixos valores (similarmente aos MORBs estudados por Sun et al. 1979), 

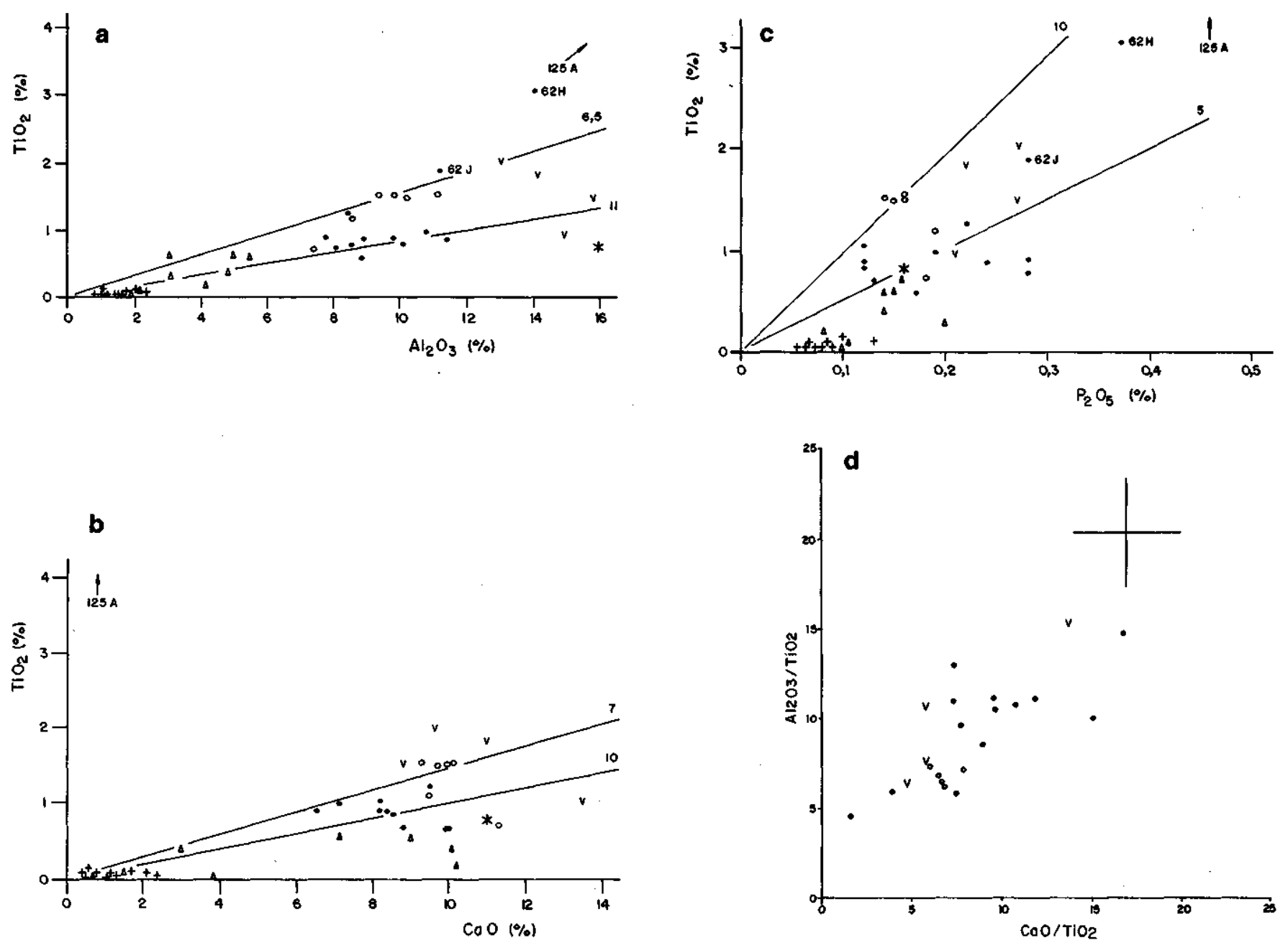

Figura 3 - Diagramas de variação dos óxidos (\% em peso) $\mathrm{Al}_{2} \mathrm{O}_{3}$, CaO e $\mathrm{P}_{2} \mathrm{O}_{5}$ em relação ao $\mathrm{TiO}$. Em (a), as amostras da sequência ultramáfica distribuem-se segundo uma faixa de pontos aproximadamente linear, definindo um discreto trend de correlação positiva. $\mathrm{O} s$ pontos referentes as camadas $\mathrm{A}$ e $\mathrm{B}$ definem alinhamentos que aproximam-se de retas $\mathrm{Al}_{2} \mathrm{O}_{3} / \mathrm{TiO}_{2}$, com valores em torno de 11 e 6,5, respectivamente. Nos gráficos (b) e (c), as amostras da sequência máfico-ultramáfica distribuemse segundo uma faixa de pontos regular definindo um fraco trend de correlação positiva. Em (b), as amostras das camadas $A$ e $\mathrm{B}$ locam-se proximamente a linhas de referência $\mathrm{CaO} / \mathrm{TiO}_{2}$, com valores ao redor de 10 e 7 , respectivamente. As rochas portadoras de olivina elou serpentina plotam junto ao eixo $x$, próximo à origem, em todos os diagramas, indicando a sua derivação de cumulados elou residual metassomática. Em (d), o conjunto das amostras das camadas $A$ e $B$ e dos anfibolitos definem um bom trend de correlação positiva. As amostras locam-se na região de baixos valores, definindo uma reta de inclinação similar a de uma série de líquidos com razões $\mathrm{CaO} / \mathrm{Al}_{2} \mathrm{O}_{3}(0,82)$ condríticos

Figure 3 - Variation diagrams of the oxides (weight percent) $\mathrm{Al}_{2} \mathrm{O}_{3}, \mathrm{CaO}$ and $\mathrm{P}_{2} \mathrm{O}_{5}$ against $\mathrm{TiO}_{2}$. In (a) the samples of the ultramafic sequence are distributed along an aproximately linear belt, defining a discreet positive correlation trend. The points relative to the beds $\mathrm{A}$ and $\mathrm{B}$ define aligmments close to the $\mathrm{Al}_{2} \mathrm{O}_{3} /$ $\mathrm{TiO}_{2}$ line with value about 11 and 6,5, respectively. In the graph (b) and (c) the samples of the mafic-ultramafic sequence are distributed along a regular belt, defining a subtle trend of positive correlation. In (b) the samples of the beds $\mathrm{A}$ and $\mathrm{B}$ plot close to the $\mathrm{CaO} / \mathrm{TiO}_{2}$ reference lines with values about 10 and 7 , respectively. The olivine and/or serpentine rocks plot close to the $\mathrm{x}$ axis, close to the origin, in all diagrams, indicating their derivation from cumulates and/ or metasomatic residua. In (d) the set of samples of beds A and B and of amphibolites define a good positive correlation trend. The samples plot in the region of low values (below the cross), defining and inclination trace similar to the liquid series with ratio $\mathrm{CaO} / \mathrm{Al}_{2} \mathrm{O}_{3}(0,82)$ about chondritic

definindo uma reta de inclinação que se aproxima de uma série de líquidos, com razões $\mathrm{CaO} / \mathrm{Al}_{2} \mathrm{O}_{3}(0,82)$ condríticas (Wänke et al. 1974), indicando que os padrões encontrados nos clorita-tremolita xistos são ainda de natureza ígnea (primária) e que, provavelmente, refletem pequenas frações de fusão do manto (Sun et al 1979). De modo similar, o número de $\mathrm{Mg}\left(\mathrm{Mg}\right.$ x $\left.100 / \mathrm{Mg}+\mathrm{Fe}^{+2}\right)$ elevado com valores entre 63 e 67 indica que a maior parte das amostras não experimentou fracionamento extensivo de cristais durante a diferenciação, representando composições próximas àquelas do líquido primário que lhes deu origem (Green 1971).
Adicionalmente, os valores das relacões Ti/Y (264) para quatro amostras, $\mathrm{Ti} / \mathrm{Zr}(114)$ e $\mathrm{Zr} / Y(2,75)$ obtidas em apenas uma das amostras da camada $\mathrm{A}$, são próximos àqueles dos condritos com razões $\mathrm{Ti} / \mathrm{Y}=256 ; \mathrm{Ti} / \mathrm{Zr}=102$ e $\mathrm{Zr} / \mathrm{Y}=$ 2,5 (Wänke et al. 1974) e muito semelhantes aos encontrados em greenstones arqueanos com $\mathrm{Ti} / \mathrm{Y}=190 ; \mathrm{Ti} / \mathrm{Zr}=110$ (Nesbitt et al. 1979).

No entanto, observa-se que a abundância dos elementos incompatíveis, $\mathrm{TiO}_{2}$ e $\mathrm{P}_{2} \mathrm{O}_{5}$ principalmente, e do $\mathrm{A}_{2} \mathrm{O}_{3}$ de modo subordinado, é maior neste grupo de rochas do que nas suítes komatiíticas arqueanas (Nesbitt \& Sun 1976, 
Smith \& Erlank 1982), diminuindo, em consequência, os valores das razões $\mathrm{CaO} / \mathrm{TiO}_{2} ; \mathrm{TiO}_{2} / \mathrm{P}_{2} \mathrm{O}_{5} ; \mathrm{Si} / \mathrm{Ti} ; \mathrm{Fe} / \mathrm{Ti} ; \mathrm{Mg} / \mathrm{Ti}$ nestas amostras.

Por outro lado, verifica-se que as variações nas razões entre os elementos para as amostras da camada A são sistemáticas e possuem estreitas correlações com o $\mathrm{MgO}$, de maneira que o aumento gradativo, embora localizadamente errático nas razões $\mathrm{CaO} / \mathrm{Al}_{2} \mathrm{O}_{3}, \mathrm{CaO} / \mathrm{TiO}_{2}, \mathrm{Si} / \mathrm{Ti}$ e $\mathrm{Mg} / \mathrm{Ti}$, são acompanhadas pelo incremento de $\mathrm{MgO}$; a diminuição nas relações $\mathrm{Al}_{2} \mathrm{O}_{3} / \mathrm{Ti}$ é acompanhada pelo incremento de $\mathrm{MgO}$, e a diminuição nas relações $\mathrm{Al}_{2} \mathrm{O}_{3} / \mathrm{TiO}_{2}, \mathrm{TiO}_{2} / \mathrm{P}_{2} \mathrm{O}_{5}, \mathrm{Fe} /$ $\mathrm{Ti}$ e Ti/Y ocorre de modo aproximadamente regular com o aumento de $\mathrm{MgO}$. Isto demonstra que o campo de variações nas razões de elementos das amostras de camada A está relacionado diretamente aos processos de fracionamento magmático.

As relações $\mathrm{Zr} / \mathrm{Nb}$ e $\mathrm{Ti} / \mathrm{Zr}$ das amostras analisadas no restante do agrupamento dos clorita e anfibólio xistos (Tab. 3) não possuem correlação aparente com o $\mathrm{MgO}$. As suas distribuições são aproximadamente regulares dentro do grupo analisado, indicando que as pequenas variações encontradas, para estas e outras razões, estão possivelmente relacionadas a processos de fracionamentos distintos nas diferentes amostras. E possível que as razões discrepantes refutam os efeitos dos diferentes graus de fusão parcial, fracionamento de cristais ou alterações metassomáticas (MR-125A, MR-62J, MR-62H), superpostas nas diversas amostras.

Assim, as relações $\mathrm{Ti} / \mathrm{Zr}$, Ti/Y, $\mathrm{Zr} / \mathrm{Y}$ e $\mathrm{CaO} / \mathrm{Al}_{2} \mathrm{O}_{3}$ condríticas, e o número de $\mathrm{Mg}$, juntamente com os conteúdos de $\mathrm{Cr}$ e Ni elevados para a camada $\mathrm{A}$, demonstram que a composição atual se aproxima do líquido primário ígneo do protólito (Nesbitt \& Sun 1976, Sun et al 1979).

Clorita-hornblenda xistos Devido ao campo de variação dos teores de $\mathrm{MgO}$ destas rochas ser pequeno, os metais de transição (Ni, Cr, $\mathrm{V}$ e $\mathrm{Co}$ ) não apresentam correlação significativa com este óxido (Figs. $2 \mathrm{a}, \mathrm{b}, \mathrm{c}, \mathrm{d}$ ). As amostras deste grupo mineralógico apresentam variações importantes nos teores desses metais, enquanto o $\mathrm{MgO}$ mantém-se quase constante. Entretanto, os trenas da distribuição das amostras deste grupo mineralógico acompanham os padrões de fracionamento magmático definidos pelo outros agrupamentos de ultramafitos. Uma das amostras possui teores de Ni superiores aos da média, anomalia atribuída possivelmente à presença do espinélio.

Nesse agrupamento de rochas, foram igualmente selecionados os dados referentes às amostras de uma banda de clorita-hornblenda xisto, denominada de camada B (MR155, MR-156, MR-157 e MR-158), para serem utilizados como traçadores petrogenéticos na identificação dos processos maiores que originaram essas litologias.

As amostras da camada B apresentam razões entre os óxidos e elementos dentro de um campo restrito de valores (Tab. 4), com variações consistentes e compatíveis com aquelas encontradas em basaltos komatíticos de suítes komatiíticas arqueanas e MORBs enriquecidos (Nesbitt \& Sun, Nesbitt et al 1979, Smith \& Erlank 1982).

Essas rochas, com exceção de uma amostra (MR-62K), apresentam discretas correlações positivas com trenas de distribuição aproximadamente linear nos gráficos $\mathrm{A}_{2} \mathrm{O}_{3} /$ $\mathrm{TiO}_{2}$ e $\mathrm{TiO}_{2} / \mathrm{CaO}$, das figuras $3 \mathrm{a}$ e b, sendo possível definir razões em torno de sete para estes óxidos. Os valores das razões encontradas representam menos da metade das relações exibidas por condritos (Wänke et al 1974), indicando que o $\mathrm{Ti}$ foi mais incompatível que o $\mathrm{Ca}$ e o $\mathrm{Al}$ nestes níveis de fusão, tornando-se enriquecido no líquido pelas baixas porcentagens de fusão ocorridas (Nesbitt et al 1979, Sun et al 1979, Barnes \& Often 1990). Essas razões possivelmente refletem padrões de natureza ígnea primária, de modo simi- lar aos basaltos magnesianos do arqueano de Minnesota (Schulz 1982), basaltos komatíticos de Barberton (Smith \& Erlank 1982) e os MORBs enriquecidos (Sun et al 1979). Os elementos $\mathrm{Ti}, \mathrm{P}, \mathrm{Zr}, \mathrm{Y}$ - nos gráficos $\mathrm{TiO}_{2} / \mathrm{P}_{2} \mathrm{O}_{5}$ (Fig. $3 \mathrm{c}$ ), $\mathrm{Zr} / \mathrm{V}$ (Fig. 4) - distribuem-se segundo faixas aproximadamente lineares com o espalhamento de pontos das amostras, sendo relacionados ou à alteração metassomática (MR-62J, MR-62H e MR-125A) ou, no caso do $\mathrm{P}$ e do Nb, à imprecisão analítica (Nesbitt \& Sun 1976, Sun et al 1979, Smith \& Erlank 1982).

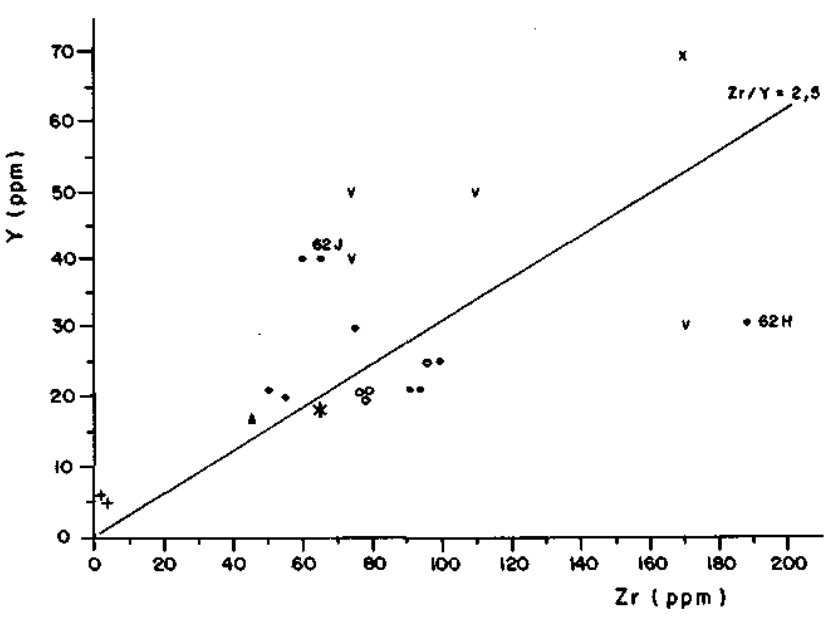

Figura 4 - Diagrama $\mathrm{Zr} / Y$ (ppm) onde observa-se distribuição irregular de algumas amostras da sequência máficoultramáfica. Nota-se alinhamento de amostras de xistos magnesianos definindo um discreto trena de correlação positiva, segundo a linha de referência $Z r / Y=2,5$ Figure 4 - Diagram $\mathrm{Zr} / \mathrm{Y}(\mathrm{ppm})$ showing an irregular distribution of some samples of the mafic-ultramafic sequence. An alignment of magnesian schists is noted, defining a discreet positive correlation trend, according to the reference line $Z r / Y=2,5$

Observa-se que as razões $\mathrm{Ti} / \mathrm{Zr}(110)$ e $\mathrm{TiO}_{2} / \mathrm{P}_{2} \mathrm{O}_{5}(10)$ dessas rochas são similares às encontradas em condritos (Wänke et al 1974) e em greenstones arqueanos (Nesbitt et al 1979). No entanto, as abundâncias dos elementos incompatíveis, principalmente $\mathrm{TiO}_{2}, \mathrm{Zr}, \mathrm{Y}, \mathrm{Nb}$, e do $\mathrm{P}_{2} \mathrm{O}_{5}$ (Tab. 5), de modo subordinado, são maiores nos clorita-hornblenda xistos que nas rochas das suítes komatíticas arqueanas. Em consequência, os valores das razões $\mathrm{Al}_{2} \mathrm{O}_{3} / \mathrm{TiO}_{2} ; \mathrm{CaO} / \mathrm{TiO}_{2}$; $\mathrm{Si} / \mathrm{Ti} ; \mathrm{Fe} / \mathrm{Ti} ; \mathrm{Mg} / \mathrm{Ti}$; $\mathrm{Ti} / \mathrm{Nb}$ e $\mathrm{Zr} / \mathrm{Nb}$ são mais baixos que a dos greenstones antigos.

As variações nas razões destes elementos estão também relacionadas aos processos de fracionamento magmático, nos quais as razões $\mathrm{CaO} / \mathrm{Al}_{2} \mathrm{O}_{3}, \mathrm{Ca} / \mathrm{TiO}_{2}, \mathrm{TiO}_{2} / \mathrm{P}_{2} \mathrm{O}_{5}, \mathrm{Mg} / \mathrm{Ti}$, $\mathrm{Ti} / \mathrm{Zr}$ aumentam de modo gradativo, localizadamente erráticas, com o incremento dos valores de $\mathrm{MgO}$; já, as razões $\mathrm{Al}_{2} \mathrm{O}_{3} / \mathrm{TiO}_{2}, \mathrm{Si} / \mathrm{Ti}, \mathrm{Fe} / \mathrm{Ti}$ e $\mathrm{Zr} / \mathrm{Nb}$ apresentam correlacões negativas com o $\mathrm{MgO}$. As relações dos elementos incompatíveis $\mathrm{Ti} / \mathrm{Nb}, \mathrm{Ti} / \mathrm{Y}$, embora apresentem consistência nos valores, não possuem correlação com o $\mathrm{MgO}$, indicando possivelmente um não-fracionamento durante a diferenciação magmática.

Finalmente, as relações $\mathrm{CaO} / \mathrm{Al}_{2} \mathrm{O}_{3}$, Ti/ $\mathrm{Zr}$ e $\mathrm{TiO}_{2} / \mathrm{P}_{2} \mathrm{O}_{5}$ condríticas e os valores elevados para o número de $\mathrm{Mg}$ e os teores de $\mathrm{Cr}$ e Ni sugerem que a composição das amostras da camada $\mathrm{B}$ correspondem aproximadamente àquela do líquido primário que thes deu origem (Nesbitt \& Sun 1976, Sun et al 1979).

Verifica-se, ainda, que os padrões de distribuição dos elementos incompatíveis normalizados ao manto primitivo (Wood et al 1981) dos xistos magnesianos (Fig. 5) são 
bastante similares ao dos $M O R B$ do tipo $\mathrm{P}$, onde são típicas as anomalias negativas de $\mathrm{K}$ e positivas as anomalias de $\mathrm{Nb}$ e La (Sun et al. 1979).

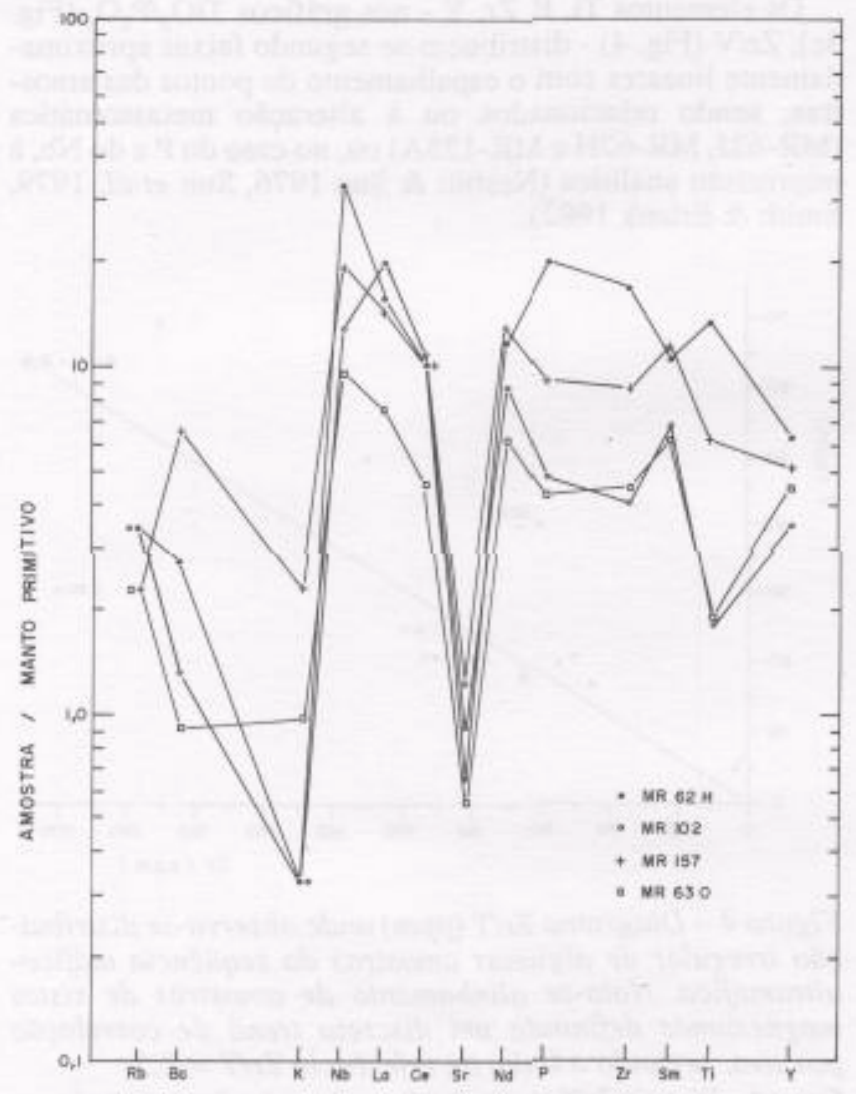

Figura 5 - Distribuição dos elementos incompatíveis de amostras de xistos magnesianos normalizados ao manto primitivo. As curvas das diferentes amostras possuem anomalias negativas de $\mathrm{Sr}$ e $\mathrm{K}$, e positivas de $\mathrm{Nb}$ e $\mathrm{La}$. Os padrões das curvas são semelhantes aos dos MORB do tipo $P$ (Sun et al. 1979)

Figure 5 - Distribution of the incompatible elements of samples from the magnesian schists normalized to primitive mantle. The curves of the dif ferent samples have negative anomalies of $\mathrm{Sr}$ and $\mathrm{K}$, and positive for $\mathrm{Nb}$ and $\mathrm{La}$. The patterns of curves are similar to the P-MORB type (Sun et al. 1979)

Anfibolitos Os metais de transição ( $\mathrm{Cr}$, Ni e $\mathrm{Co}$ ) ocorrem em teores compatíveis com aqueles encontrados em suítes toleíticas antigas (Nesbit \& Sun 1976). Tais elementos se localizam próximo aos vértices nos gráficos $\mathrm{Cr} / \mathrm{MgO}$, $\mathrm{Ni} / \mathrm{MgO}$ e $\mathrm{Co} / \mathrm{MgO}$ das figuras $2 \mathrm{a}, \mathrm{b}, \mathrm{d}-\mathrm{e}$, embora haja ausência de correlação aceitável, acompanham o trend de fracionamento do restante da sequência. $\mathrm{O}$ vanádio, no gráfico $\mathrm{V} / \mathrm{MgO}$ da figura $2 \mathrm{c}$, é o elemento que apresenta a maior dispersão, com três amostras próximas ao vértice (abaixo do trend principal) e outras duas com teores anómalos, posicionados acima do trend de diferenciação dos demais ultramafitos.

Os anfibolitos, com exceção de uma amostra (MR-151), possuem razões entre os óxidos e elementos $\left(\mathrm{CaO} / \mathrm{Al}_{2} \mathrm{O}_{3}\right.$, $\mathrm{Al}_{2} \mathrm{O}_{3} / \mathrm{TiO}_{2}, \quad \mathrm{CaO} / \mathrm{TiO}{ }_{2}, \quad \mathrm{TiO}_{2} / \mathrm{P}_{2} \mathrm{O}_{5}, \quad \mathrm{FeO} / \mathrm{Fe}_{2} \mathrm{O}_{3}, \mathrm{MgO} / \mathrm{FeO}$, $\mathrm{Zr} / \mathrm{Y}$ e Ti/Y (Tab. 4), próximas aos valores encontrados em toleítos arqueanos do tipo $\mathrm{TH}_{\mathrm{z}}$ (Condie 1981). Alguns valores discrepantes dessas amostras são assinalados pelas anomalias positivas de $\mathrm{Cr}$ e Ni, e razões elevadas de $\mathrm{FeO} / \mathrm{Fe}_{2} \mathrm{O}_{3}$.

A média das razões Ti/Zr (104) é mais elevada do que aquelas dos $\mathrm{TH}_{2}$, porém, aproxima-se dos valores encontra- dos em condritos com relações $\mathrm{Ti} / \mathrm{Zr}=102$ (Wänke et al. 1974), indicando que a composição destes anfibolitos corresponde ainda àquela dos líquidos primitivos, gerados por fusão parcial do manto (Nesbitt \& Sun 1978, Sun et al. 1979), muito embora os valores relativamente baixos dos números de $\mathrm{Mg}$ (42-45) demonstrem o elevado grau de fracionamento dessas amostras.

As variações nos valores das razões $\mathrm{CaO} / \mathrm{Al}_{2} \mathrm{O}_{3}, \mathrm{TiO}_{2} /$ $\mathrm{P}_{2} \mathrm{O}_{5}, \mathrm{Ti} / \mathrm{Zr}$ e das razões $\mathrm{Ti} / \mathrm{Y}, \mathrm{Zr} / \mathrm{Y}$ dessas amostras relacionam-se ao fracionamento magmático, onde os primeiros valores possuem correlação positiva com o $\mathrm{MgO}$ e os últimos co-variações negativas com este óxido.

ELEMENTOS TERRAS RARAS As concentrações dos elementos terras raras (ETR), obtidas em 22 amostras da sequência máfico-ultramáfica, bem como os valores das relações $(\mathrm{La} / \mathrm{Yb}) \mathrm{N} ;(\mathrm{La} / \mathrm{Sm}) \mathrm{N}$ e $(\mathrm{Yb} / \mathrm{Gd}) \mathrm{N}$ são apresentados nas tabelas 5 e 6 . As amostras assinaladas com asterisco $(*)$ foram analisadas no laboratório do King's College - Inglaterra, pelo segundo autor, e o restante no laboratório da GEOSOL, Belo Horizonte - MG, pelo método descrito por Dutra (1984). As curvas de abundância dos ETR da rocha total foram construídas a partir da normalização ao condrito $\mathrm{Cl}$ (Evensen et al. 1978) e, juntamente com os teores de $\mathrm{MgO}$ (em base anidra) das amostras, podem ser vistas nas figuras 6 a 9 .

Os xistos magnesianos possuem conteúdos de ETR relativamente baixos, com ETR total entre 30,41 e 70,13 ppm e razões $(\mathrm{La} / \mathrm{Yb}) \mathrm{N}$ entre 1,36 e 8,37 (excluindo as amostras MR-62J, MR-84F das tabelas citadas). Tais valores são semelhantes e ligeiramente superiores àqueles encontrados em rochas komatíticas, aproximadando-se mais dos

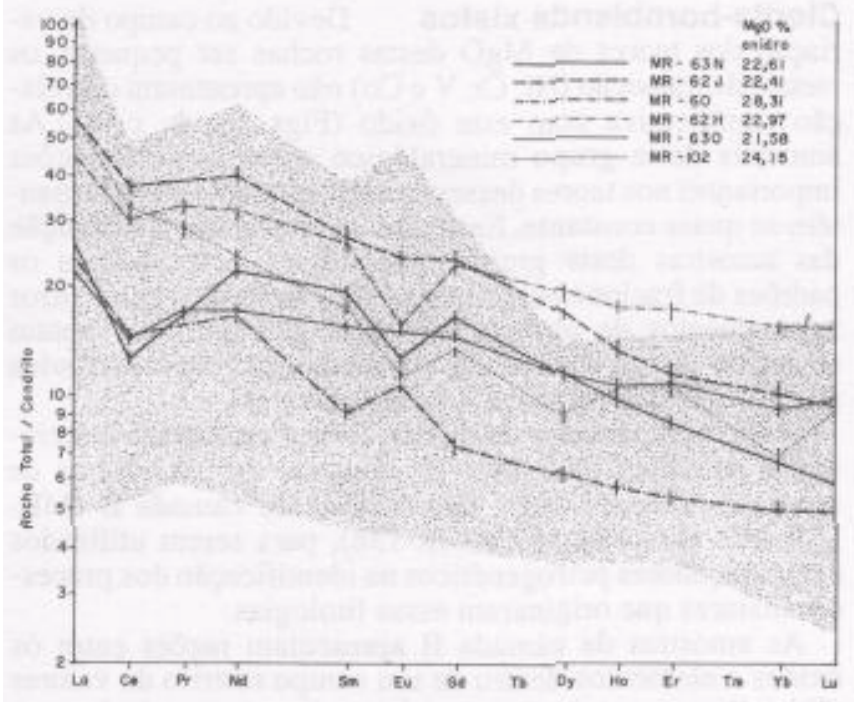

Figura 6 - Curvas de abundância dos elementos terras raras (ETR) de clorita-anfibólio xistos e xistos magnesianos com talco da Sequência Máfico-Ultramáfica do Complexo Cambaizinho, normalizados aos condritos, e envelope de distribuição dos ETR de komatiitos de Crixás - GO (amostra $\left.n^{\circ} 1\right)$ (Figueiredo \& Kronberg 1988) e o limite inferior pelos komatiitos da região de Piumhi (amostra A 24C) (Jahn \& Schrank 1983) e Crixás (NPA - 2) (Arndt et al. 1989) Figure 6 - Rare earth element (REE) abundance curves of the chloriteamphibole schists and magnesian schists with tale of Complexo Cambaizinho Mafic-Ultramafic Sequence, normalized to chondrites and distribution envelope of REE of Brazilian komatiites. The upper limit is demarcated by komatiites from Crixás - GO (samples no 1) (Figueiredo \& Kronberg 1988) and a lower limit by the komatiites from Piumhi (samples A24C) (Jahn \& Schrank 1983) and Crixás (NPA-2) (Arndt et al. 1989) 
Tabela 5 - Elementos terras raras (ppm) dos xistos magnesianos, olivina-talco ultramafitos e serpentinitos da Sequência Máfico-Ultramáfica do Complexo Cambaizinho, São Gabriel - RS

Table 5 - Rare earth elements (ppm) of the magnesian schists, olivine-talc ultramafites and serpentinites of the Mafic-Ultramafic Sequence of Cambaizinho Complex, São Gabriel - RS

\begin{tabular}{|c|c|c|c|c|c|c|c|c|c|}
\hline \multirow[t]{2}{*}{$\begin{array}{l}\text { Amostras } \\
\text { (MR) }\end{array}$} & \multicolumn{4}{|c|}{$\begin{array}{l}\text { Clorita-Anfibólio } \\
\text { Xistos }\end{array}$} & \multicolumn{2}{|c|}{$\begin{array}{c}\text { Clorita-Talco } \\
\text { Tremolita } \\
\text { Xistos }\end{array}$} & \multirow{2}{*}{$\begin{array}{c}\begin{array}{c}\text { Clorita } \\
\text { Antoflita- } \\
\text { Talco } \\
\text { Xisto }\end{array} \\
\mathbf{8 4 F}\end{array}$} & \multirow{2}{*}{$\begin{array}{c}\begin{array}{c}\text { Olivina- } \\
\text { Talco- } \\
\text { Utiramafito }\end{array} \\
101\end{array}$} & \multirow{2}{*}{ Serpentinito } \\
\hline & $63 \mathrm{~N}$ & 62.J & $630^{*}$ & $62 \mathrm{H}^{*}$ & 60 & $102^{*}$ & & & \\
\hline La & 6,60 & 14,00 & 5,39 & 11,20 & 6.00 & 14,12 & 1.60 & 1,10 & 0,80 \\
\hline $\mathrm{Ce}$ & 8,00 & 24,00 & 8,95 & 19,55 & 9,30 & 20,62 & 1,70 & 1,80 & 1,60 \\
\hline Pr & . & - & 1,63 & 3,21 & - & 2,74 & - & - & - \\
\hline Nd & 10,60 & 19,10 & 8.09 & 15,49 & 7,80 & 11,35 & 1,40 & 1,00 & 0,80 \\
\hline Sm & 3,00 & 4,20 & 2,40 & 4,12 & 1,40 & 2,64 & 0,24 & 0,22 & 0.15 \\
\hline Eu & 0,73 & 1,40 & 0,87 & 0,91 & 0,62 & 0,64 & 0,13 & 0,20 & 0,10 \\
\hline Gd & 3,40 & 4,90 & 2,95 & 2,79 & 1,50 & 2,81 & $<0,20$ & 0,22 & 0.20 \\
\hline Dy & 2,90 & 4,30 & 2,90 & 4,92 & 1,60 & 2,26 & 0,19 & 0,22 & 0,13 \\
\hline $\mathrm{Ho}$ & 0,55 & 0,74 & 0,61 & 0,99 & 0,33 & 0.60 & 0,03 & 0,03 & 0,02 \\
\hline Er & 1,40 & 1,90 & 1,79 & 2,87 & 0,90 & 1.79 & 0,11 & 0,08 & 0,10 \\
\hline $\mathrm{Yb}$ & 1,10 & 1.70 & 1,52 & 2,56 & 0,83 & 1,14 & 0,18 & 0,11 & 0.17 \\
\hline Lu & 0,15 & 0,24 & 0,25 & 0,39 & 0,13 & 0,23 & 0,04 & 0,02 & 0,03 \\
\hline Total & 38,43 & 76.48 & 35,35 & 71,00 & 30,41 & 60,94 & 5,82 & 5,00 & 4,10 \\
\hline$(\mathrm{La} / \mathrm{Yb}) \mathrm{N}$ & 4,05 & 5,56 & 2,39 & 2,95 & 4,88 & 8,37 & 6,00 & 6,72 & 3,17 \\
\hline$(\mathrm{La} / \mathrm{Sm}) \mathrm{N}$ & 1,39 & 2,10 & 1,41 & 1.71 & 2,70 & 3,37 & 4,19 & 3,15 & 3.37 \\
\hline$(\mathbf{Y b} / \mathbf{G d}) \mathrm{N}$ & 0,40 & 0,43 & 0,64 & 0,66 & 0,69 & 0,50 & 1,11 & 0,62 & 1,05 \\
\hline
\end{tabular}

(*) Dados obtidos na Southampton University - Inglaterra

Tabela 6 - Elementos terras raras (ppm) dos xistos magnesianos, anfibolitos e metagabros da Sequência Máfico-Ultramáfica do Complexo Cambaizinho, São Gabriel-RS

Table 6 - Rare earth elements (ppm) of the magnesian schists, amphibolite and metagabbros of the Mafic-Ultramafic Sequence of Cambaizinho Complex, São Gabriel - RS

\begin{tabular}{|c|c|c|c|c|c|c|c|c|c|c|c|c|c|}
\hline \multirow{2}{*}{$\begin{array}{c}\text { Amostras } \\
\text { (MR) }\end{array}$} & \multicolumn{4}{|c|}{ Clorita-Tremolita Xistos } & \multicolumn{4}{|c|}{ Clorita-Hornblenda Xistos } & \multicolumn{3}{|c|}{ Anfibolitos } & \multicolumn{2}{|c|}{ Metagabros } \\
\hline & 145 & 147 & 148 & 149 & 155 & 156 & $157^{\star}$ & 158 & $62 \mathrm{R}$ & $111^{\star}$ & $79 \mathrm{~A}$ & $83 C^{\star}$ & $89^{\star}$ \\
\hline La & 9,10 & 14,80 & 9,90 & 7,80 & 8,60 & 9,80 & 10,41 & 3,60 & 6,90 & 17,39 & 11,10 & 3,59 & 2,17 \\
\hline $\mathrm{Ce}$ & 13,80 & 17,40 & 15,20 & 13,70 & 15,50 & 18,40 & 19,36 & 11,60 & 15,80 & 39,66 & 24,00 & 8,74 & 5,57 \\
\hline $\operatorname{Pr}$ & - & - & - & - & - & - & 3,51 & - & - & 4,66 & - & 1,24 & 0,85 \\
\hline Nd & 13,10 & 15,90 & 13,50 & 10,90 & 12,30 & 13,90 & 17,01 & 12,70 & 14,50 & 21,55 & 16,30 & 6,99 & 5,18 \\
\hline $\operatorname{sm}$ & 3,40 & 3,50 & 3,00 & 2,70 & 3.10 & 3,40 & 4,44 & 3,00 & 3,60 & 5,05 & 4,10 & 2,23 & 1,79 \\
\hline Eu & 0,97 & 1,10 & 1,00 & 0,87 & 1,10 & 1,10 & 1,32 & 1,10 & 1,30 & 1,71 & 1,40 & 0,95 & 0,83 \\
\hline $\mathrm{Gd}$ & 3,30 & 3,30 & 3,10 & 2,70 & 3,10 & 3,30 & 4,75 & 3,00 & 3,90 & 5,17 & 4,10 & 2.71 & 2,21 \\
\hline Dy & 3.10 & 2,90 & 2,80 & 2,50 & 2,80 & 2,80 & 4,15 & 2,70 & 3.60 & 4,87 & 3,40 & 2,82 & 2,28 \\
\hline Ho & 0,54 & 0,49 & 0,60 & 0,42 & 0,52 & 0,44 & 0,82 & 0,45 & 0,58 & 1,02 & 0,55 & 0,62 & 0,50 \\
\hline $\mathrm{Er}$ & 1,70 & 1.40 & 1,60 & 1,20 & 1,40 & 1,30 & 2,25 & 1.40 & 1,60 & 2,72 & 1,60 & 1,72 & 1,43 \\
\hline $\mathrm{Yb}$ & 1,20 & 1,00 & 1,20 & 1,00 & 1,10 & 1,00 & 1,81 & 1,10 & 1,20 & 2,49 & 1,30 & 1.53 & 1,26 \\
\hline Lu & 0,17 & 0,15 & 0,16 & 1,40 & 0,14 & 0,12 & 0,30 & 0,14 & 0,15 & 0,38 & 0,15 & 0,24 & 0,20 \\
\hline Total & 50.38 & 61,94 & 52,06 & 45,19 & 49,66 & 55,56 & 70,14 & 40,79 & 53,13 & 106,67 & 68,00 & 33,38 & 24,27 \\
\hline$(\mathrm{La} / \mathrm{Yb}) \mathrm{N}$ & 5,12 & 9,99 & 5,57 & 5,26 & 5,28 & 6,61 & 3,88 & 2,21 & 3,88 & 4,71 & 5,77 & 1,58 & 1,16 \\
\hline$(\mathrm{La} / \mathrm{Sm}) \mathrm{N}$ & 1,68 & 2,66 & 2,08 & 1,82 & 1,75 & 1,81 & 1,48 & 0,76 & 1,21 & 2,17 & 1,70 & 1,01 & 0,76 \\
\hline$(\mathrm{Yb} / \mathrm{Gd}) \mathbf{N}$ & 0,45 & 0,38 & 0,48 & 0,46 & 0.44 & 0,38 & 0,47 & 0.45 & 0,38 & 0.60 & 0,39 & 0,70 & 0.71 \\
\hline
\end{tabular}

(*) Dados obtidos na Southampton University - Inglaterra 
basaltos komatiíticos; porém, bastante inferiores aos das suítes toleíticas de outros ambientes geotectônicos (Culler \& Graf 1984). Os anfibolitos, metabasaltos e metagabros associados possuem um conteúdo de ETR total variável, entre 24,27 e 106,68 ppm, concentrações essas compatíveis com aquelas obtidas nos toleítos associados às suítes komatiíticas, e razões $(\mathrm{La} / \mathrm{Yb}) \mathrm{N}$ entre 1,16 e 5,77 semelhantes e pouco superiores às destes toleítos (Cullers \& Graf 1984).

As rochas portadoras de olivina e/ou serpentina, juntamente com a amostra de talco xisto (MR-84F), apresentam abundâncias globais de ETR entre 4,10 e 5,82 ppm, com padrões de distribuição semelhantes àqueles encontrados nos peridotitos (dunitos) de Shikoku-Japão e Twin Sister Washington (Frey et al. 1971 apud Cullers \& Graf 1984) e da Noruega (Garmann et al. 1975).

Considerando a sequência máfíco-ultramáfica como um todo, verifica-se que o conteúdo de ETR total aumenta em ordem gradativa, quase regular, desde as rochas portadoras de olivina e/ou serpentina, xistos magnesianos com talco, clorita anfibólio xistos, até anfibolitos, tendendo a acompanhar a diminuição do $\mathrm{MgO}$. A única exceção a essas variações é apresentada por duas amostras de metagabros que apresentam concentrações relativamente baixas de ETR total (Tab. 6). Entretanto, no interior dos agrupamentos de xistos magnesianos, ocorrem relações inversas, onde o conteúdo de ETR total das amostras aumenta com o incremento de $\mathrm{MgO}$, exceto para o grupo de xistos magnesianos com talco, em que a correlação entre a concentração de ETR total e o $\mathrm{MgO}$ é negativa. De forma contrária, a razão $(\mathrm{La} / \mathrm{Yb}) \mathrm{N}$ apresenta, de modo genérico, correlação positiva com o $\mathrm{MgO}$ para o grupo dos xistos magnesianos com talco e correlação negativa com este óxido para o restante dos grupos de xistos magnesianos.

As fases minerais metamórficas das rochas ultramáficas que concentram os ETR são os anfibólios, cloritas, talco, esfeno, ilmenita, rutilo, apatita e espinélios. Nos xistos magnesianos com talco e nos clorita-anfibólio xistos, existe correlação positiva entre a porcentagem de clorita e o teor de ETR total. Isto significa que a clorita é o mineral de alteração secundária (metamórfica) que estabiliza os ETR em maior quantidade nessas rochas. Observações semelhantes foram feitas por Ludden \& Thompson (1979), em basaltos submarinos, e comprovadas por experimentos de Menzies et al. (1979). O talco é o mineral que concentra os menores teores de ETR total nas rochas da sequência. As fases minerais primárias principais que foram destruídas durante a deformação, o metamorfismo (alteração secundária) e a consequente geração dos xistos magnesianos supõem uma paragênese à base de clonopiroxênio especialmente, olivina e vidro (?), em proporções menores.

A avaliação da mobilidade relativa dos ETR nas rochas máficas e ultramáficas metamorfízadas e alteradas é um assunto ainda em aberto e bastante controvertido (Frey 1984, Sun \& Nesbitt 1978, Beswick 1982, Humphris 1984 entre outros). Os estudos feitos indicam que não existe uma relação simples entre a baixa mobilidade relativa dos ETR e o grau metamórfico, ou o tipo de alteração intempérica ocorrida (Humphris 1984). De maneira genérica, considera-se que a alteração secundária modifica os padrões de ETR e, especialmente, as abundâncias de Ce e Eu.

Os padrões irregulares nas curvas de concentração de ETR das amostras de clorita-anfibólio xistos (MR-62J e MR-62H) são atribuídos aos processos de alteração secundários, observados na petrografia e na química dos elementos maiores e traços. De outro modo, a amostra de clorita-anfibólio-talco xistos (MR-84F) apresenta teores de ETR muito baixos e compatíveis com os encontrados em cumulados de olivina e/ou ortopiroxênios. Assim, essas três amostras não foram levadas em consideração no estabeleci- mento dos valores referentes aos limites superiores e inferiores do conteúdo de ETR dos xistos magnesianos dessa região, para efeitos de comparação.

As curvas de abundância dos ETR das amostras de xistos magnesianos com talco e clorita-anfibólio xistos, mostradas na figura 6, apresentam padrões com distribuição irregulares, com anomalias negativas de Ce e variáveis de Eu. As razões entre os elementos $\mathrm{Ti} / \mathrm{Zr}$ e $\mathrm{Ti} / \mathrm{Y}$ indicam que estes padrões são oriundos da alteração secundária (Nesbitt \& Sun 1976, Sun \& Nesbitt 1978). Entretanto, as razões entre os óxidos $\left(\mathrm{CaO} / \mathrm{Al}_{2} \mathrm{O}_{3}, \mathrm{Al}_{2} \mathrm{O}_{3} / \mathrm{TiO}_{2}\right.$ e $\left.\mathrm{CaO} / \mathrm{TiO}_{2}\right)$, listados nas tabelas 2 e 3 , com valores próximos aos obtidos em suítes komatíticas arqueanas (Nesbitt \& Sun 1976), demonstram que os padrões (primários) dominantes, de enriquecimento em ETRL e empobrecimento em ETRP, apesar das modificações, foram ainda parcialmente preservados nessas rochas. $\mathrm{O}$ envelope de distribuição dos ETR em rochas komatíticas do Brasil, construídos com base nos dados de Jahn \& Schrank (1983), Figueiredo \& Kronberg (1988) e Arndt et al. (1989), foram plotados na figura 6 para comparação. Observa-se que o enriquecimento em ETRL é comum às sequências em comparação.

As camadas A e B foram novamente selecionadas para estudar os principais processos petrogenéticos geradores destas rochas, tendo em vista que as suas amostras apresentam regularidade nos perfis de abundância de ETR (Figs. 7a, b).

Os perfis de concentração de ETR, das amostras de clorita-tremolita xistos da camada $\mathrm{A}$, são fortemente fracionados, com razões $(\mathrm{La} / \mathrm{Yb}) \mathrm{N}$ entre 5,12 e 9,99 e curvas inclinadas, com formas levemente convexas para cima, para os ETRL, e suavemente côncavas para cima, para os ETRP. Dessa forma, o padrão de fracionamento dos ETRP, com razão $(\mathrm{Yb} /$ Gd)N $=0,38$ a 0,48 , é maior que o padrão de fracionamento dos ETRL, com razão $(\mathrm{La} / \mathrm{Sm})_{\mathrm{N}}=1,68-2,66$.

As curvas de abundância dos ETR normalizados aos condritos dos clorita-hornblenda xistos da camada B são igualmente fracionadas, com razões $(\mathrm{La} / \mathrm{Yb}) \mathrm{N}$ entre 2,21 e 0,61 , e padrões de fracionamento com curvas menos inclinadas, de forma levemente côncava para cima (quase planas) para os ETRP, com razões $(\mathrm{Yb} / \mathrm{Gd}) \mathrm{N}=0,38$ a 0,47.

Trabalhos realizados em pares de amostras vizinhas de rochas máficas e ultramáficas de várias regiões, visando avaliar a mobilidade dos ETR, demonstram que as amostras inalteradas (consideradas normais) são as que apresentam padrões mais enriquecidos em ETRL (Sun \& Nesbitt 1978), significando que, de modo geral, durante a alteração secundária, as rochas máficas e ultramáficas perdem ETRL. Neste sentido, o grau de enriquecimento de ETRL das camadas A e B não deve representar padrões de alteração secundárias atribuídos ao metamorfismo e/ou intemperismo. Assim, na medida em que essas amostras, em cada camada, apresentam regularidade nas curvas de concentração de ETR normalizadas ao condrito e possuem, ainda, razões $\mathrm{Ti} / \mathrm{Zr}, \mathrm{Ti} / \mathrm{Y}$, $\mathrm{TiO}_{2} / \mathrm{P}_{2} \mathrm{O}_{5}$ e $\mathrm{CaO} / \mathrm{Al}_{2} \mathrm{O}_{5}$ próximas àquelas dos valores condríticos (Wänke et al. 1974), acredita-se que estes padrões de ETR não sofreram modificações globais substanciais, correspondendo ainda aos valores existentes no líquido primário que lhes deu origem.

As modificações ocorridas resumem-se a anomalias negativas de Ce (especialmente), nas amostras das duas camadas, as quais indicam que estas rochas foram alteradas em ambientes submarinos e contaminados pela água do mar. Anomalias negativas de Ce ocorrem em ambiente marinho (Frey 1977), visto que este elemento é empobrecido nesse ambiente, devido a sua oxidação para $\mathrm{Ce}^{+4}$ e ao seu fracionamento, durante a formação de nódulos de $\mathrm{Mn}$ e de sedimentos metalíferos (Piper 1974, Ludden \& Thompson 1979). As ocorrências de anomalias positivas e negativas de Eu para as amostras de uma mesma camada (B) indicam que 

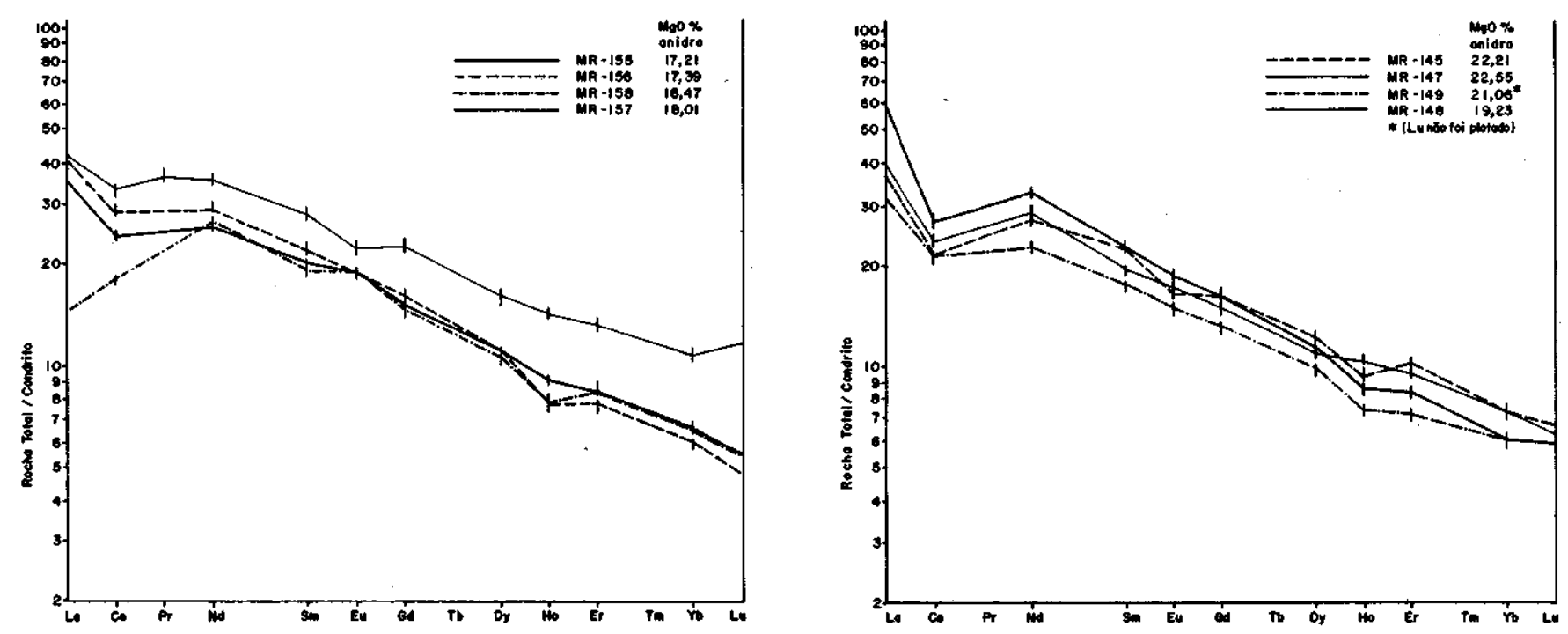

Figura 7 - Perfis de concentração dos elementos terras raras em amostras de clorita-tremolita xistos da camada A (a) e de clorita hornblenda xistos da camada $B$ (b), normalizados aos condritos. Nota-se regularidade na distribuição dos ETR nas diferentes amostras e seu enriquecimento relativo em terras raras leves

Figure 7 - Rare earth element (REE) abundance curves for the chlorite-tremolite schist samples of bed A (a) and for the chlorite-hornblende schists of bed $\mathrm{B}$ (b) normalized to chondrites. Note a REE regular distribution in different samples and their relative enrichment in light rare earth elements

estes padrões estão mais relacionados à alteração que aos processos petrogenéticos primários (Hawkesworth \& O'Nions 1977, Sun \& Nesbitt 1978), envolvendo a separação ou a presença de plagioclásio, como resíduo de fusões de líquidos com alto MgO (Green \& Ringwood 1967). No entanto, a ocorrência de anomalias negativas de $\mathrm{Sr}$, sistemática em gráficos de abundâncias de elementos incompatíveis, normalizados ao manto primitivo (Fig. 5), indica que parte das anomalias negativas de Eu, discutidas acima, podem estar relacionadas ao fracionamento do plagioclásio em condições crustais. A amostra mais alterada dessa camada (MR-158) possui anomalia positiva de Eu e anomalias negativas de La e Ce, simultaneamente (Fig. 7).

O clinopiroxênio representa, provavelmente, uma das fases precursoras dominantes nas camadas A e B, porque os perfis de abundância de ETR, nessas amostras, são similares às concentrações de ETR neste mineral, com valores de 20 a 50 vezes o do padrão condrítico que, em determinadas situações, possuem preferência pelos ETRL (Haskin 1984). Durante o metamorfismo e deformação, os clinopiroxênios transformam-se em anfibólio cálcico (hornblenda, tremolita, actinolita). A olivina tansforma-se em serpentina e/ou, juntamente com o vidro da matriz (?), em clorita, dando origem a esses xistos. Assim, o controle de conteúdo dos ETRL está relacionado à quantidade de anfibólio e clorita, principalmente, e, de modo subordinado, à quantidade de acessórios (esfeno, apatita e opacos), tornando-se dificil, com o número de amostras aqui estudadas, determinar com exatidão qual o mineral que comanda a distribuição de ETR neste grupo de rochas.

Os padrões de abundância, com curvas aproximadamente paralelas para as amostras das camadas A e B, com poucas modificações na inclinação dos ETRL (La/Sm)N, favorecem o modelo de cristalização fracionada no interior de cada camada (Whitford \& Arndt 1979, Arndt \& Jenner 1986). Adicionalmente, as relações $\mathrm{TiO}_{2} / \mathrm{P}_{2} \mathrm{O}_{5}$, nas amostras das camadas A e B, diminuem com o aumento do grau de enriquecimento em ETRL ( $\mathrm{La} / \mathrm{Sm}) \mathrm{N}$, de modo aproximadamente regular. Além disso, as razões $\mathrm{Zr} / \mathrm{Nb}$, nas amostras da camada A, possuem correlações negativas com os valores de
(La/Sm)N. Estas variações nas razões são comuns em processos petrogenéticos, geradores de MORB (Sun et al 1979), constituindo-se, portanto, em bons indicadores de fracionamento primário nestes xistos magnesianos.

As relações $\mathrm{Ti} / \mathrm{Zr}$ (camadas $\mathrm{A}$ e $\mathrm{B}$ ), $\mathrm{Ti} / \mathrm{Y}$ e $\mathrm{TiO}_{2} / \mathrm{P}_{2} \mathrm{O}_{5}$ (camadas A e B, respectivamente) condríticas, além dos números de $\mathrm{Mg}$ elevados, e os valores de $\mathrm{Ni}$ e $\mathrm{Cr}$ para estes materiais, indicam que sua composição atual corresponde aproximadamente ao do líquido primário que lhes deu origem (Nesbitt et al 1979, Sun 1984). Assim, o enriquecimento em elementos incompatíveis (ETRL, $\mathrm{Zr}, \mathrm{Y}, \mathrm{Nb}, \mathrm{TiO}_{2}$ e $\left.\mathrm{P}_{2} \mathrm{O}_{5}\right)$, juntamente com os valores das relações $\left(\mathrm{A}_{2} \mathrm{O}_{3} /\right.$ $\mathrm{TiO}_{2}, \mathrm{Ti} / \mathrm{Y}, \mathrm{Zr} / \mathrm{Nb}$ ), demonstra que estes xistos magnesianos podem ter sido derivados de: (I) contaminação crustal; (II) fracionamento de granada e clinopiroxênio; (III) alteração secundária; (IV) características herdadas da fonte (manto); ou (V) fusão seletiva do manto, representando líquidos extraídos precocemente.

Padrões de enriquecimento em ETRL (La/Sm)N, semelhantes aos desses xistos magnesianos, são encontrados em basaltos komatíticos de Kambalda (Hanging-wall Basalts), do oeste da Austrália, sendo atribuídos à contaminação crustal (Arndt \& Jenner 1986). Entretanto, este processo não explicaria adequadamente os elevados teores de $\mathrm{TiO}_{2}$ e nem os padrões empobrecidos de ETRP desses xistos. De qualquer modo, a hipótese de contaminação crustal (I) é de difícil avaliação, pela inexistência de dados de isótopos de $\mathrm{Nd}$ nessas rochas.

A presença de granada e clonopiroxênio, como resíduos da fusão parcial na fonte (hipótese II), poderia reduzir as razões $(\mathrm{Yb} / \mathrm{Gd}) \mathrm{N}$ (granada e clinopiroxênio) e elevar as razões (La/Sm)N (clinopiroxênio) dos líquidos gerados (Sun $\&$ Nesbitt 1978). No entanto, é difícil supor que grandes quantidades de clonopiroxênio e granada permaneçam no resíduo de líquidos com estes teores de $\mathrm{MgO}$ (17 a 22,5\%). De modo alternativo, o fracionamento de cristais de granada em grandes profundidades poderia explicar os padrões $(\mathrm{Yb} /$ Gd)N desses xistos (Sun \& Nesbitt 1978, Barnês \& Often 1990), permanecendo, contudo, inexplicável, neste caso, os valores elevados para $(\mathrm{La} / \mathrm{Sm}) \mathrm{N}$. 
A alteração secundária (III) poderia mudar drasticamente os padrões de ETR dos protolitos dessas rochas. No entanto, a regularidade e consistência das curvas de abundância dos ETR normalizados ao condrito e os valores das razões $\mathrm{Ti} / \mathrm{Zr}$ e Ti/Y das camadas A e B, conforme discutido anteriormente, eliminam tal hipótese.

A hipótese (IV) de que as características químicas das camadas $\mathrm{A}$ e $\mathrm{B}$ correspondem à composição do manto primitivo (enriquecido) é mais atrativa, porque o padrão de ETRL de líquidos altamente magnesianos não pode ser significativamente diferente do de sua fonte (Sun \& Nesbitt 1978). Além disso, o enriquecimento de ETRL em basaltos komatiíticos e komatiitos ocorre em várias regiões de muitos continentes. Na América do Sul, são conhecidos exemplos em Piumhi - MG (Jahn \& Schrank 1983, Schrank 1986), Seringa - PA (Huhn et al. 1986, Choudhuri 1989), Crixás - GO (Figueiredo \& Kronberg 1988, Arndt et al 1989) e Alpinópolis - MG (Szabó apud Schrank \& Choudhuri 1989). Na Austrália, ocorrem nas localidades de Negri, Menzies e Mt. Monger (Sun \& Nesbitt 1978) no Zimbábue, na região de Shabani-Belingwe (Nisbet et al. 1977, Sun \& Nesbitt 1978), nas supracrustais IsuaGroenlândia (Sun \& Nesbitt 1978) e nos Estados Unidos, na região de Minnesota (Schulz 1982) e na Noruega, no Greenstone Belt de Karasjok (Barnes \& Often 1990).

$\mathrm{Na}$ maior parte dessas áreas, o enriquecimento em ETRL das amostras é atribuído ao enriquecimento da fonte (Nesbitt \& Sun 1976, Nesbitt et al 1979, Sun \& Nesbitt 1978, Jahn \& Schrank 1983, Figueiredo \& Kronberg 1988, Schrank \& Choudhuri 1989 entre outros) ou a pequenas frações de fusão seletiva do manto normal (hipótese V), onde são extraídas grandes quantidades de elementos incompatíveis, gerando líquidos precoces, com baixas razões $\mathrm{Al}_{2} \mathrm{O}_{3} / \mathrm{TiO}_{2} \mathrm{e}$ $\mathrm{CaO} / \mathrm{TiO}_{2}($ Sun \& Nesbitt 1978, Nesbitt et al 1979, Nesbitt \& Sun 1976, Barnes \& Often 1990).

A partir desses modelos, pode-se concluir que as camadas A e B foram derivadas de uma fonte enriquecida em elementos incompatíveis, através de pequenas porcentagens de fusão parcial, embora suficientes para produzirem líquidos com os conteúdos de MgO komatííticos (17 a 22,5\%), encontrados nessas rochas. Os diferentes valores médios para as razões $((\mathrm{La} / \mathrm{Sm}) \mathrm{N}=2,06$ e 1,45$) ;\left(\mathrm{TiO}_{2} / \mathrm{P}_{2} \mathrm{O}_{5}=7,22\right.$ e 10,02); $\left(\mathrm{Al}_{2} \mathrm{O}_{3} / \mathrm{TiO}_{2}=10,5\right.$ e 6,7$)$ e $\left(\mathrm{CaO} / \mathrm{TiO}_{2}=9,7\right.$ e 6,5$)$ para as camadas A e B, respectivamente; por outro lado, indicam que os graus de fusão foram suavemente diferenciados para cada camada.

Todas as rochas máficas analisadas possuem anomalias positivas de Eu, sendo que, nas amostras de metagabros, estas anomalias $\left(\mathrm{Eu} / \mathrm{Eu}^{*}=1,19\right.$ a 1,28$)$ se acentuam. Isto indica que o fracionamento do plagioclásio representou um processo importante na geração dessas litologias e que, nos metagabros, o plagioclásio é uma fase mineral cumulática (Cullers \& Graf 1984).

Os anfibolitos (metabasaltos) exibem padrões de ETR enriquecidos com $(\mathrm{La} / \mathrm{Sm}) \mathrm{N}=1,21$ a 2,1 Te fracionamento de ETRP com $(\mathrm{Yb} / \mathrm{Gd}) \mathrm{N}=0,38$ a 0,60 . Esses padrões são similares ao dos toleítos enriquecidos - $\mathrm{TH}_{\mathrm{Z}}$ (Condie 1981). As curvas de abundância normalizadas ao condrito (Fig. 8) são aproximadamente paralelas nas três amostras, demonstrando que os anfibolitos foram gerados por cristalização fracionada de um mesmo magma (Whitford \& Arndt 1979).

Os metagabros exibem curvas de abundância normalizadas, com valores de 10 vezes os condritos, de forma convexa para cima, e pouco fracionamento de ETR com razões $(\mathrm{La} / \mathrm{Yb}) \mathrm{N}=1,16$ a 1,58 , e padrões de ETRL quase planos, pouco empobrecidos $(\mathrm{La} / \mathrm{Sm}) \mathrm{N}=0,76$ a 1,01, além de pouco fracionamento de ETRP com $(\mathrm{Yb} / \mathrm{Gd}) \mathrm{N}=0,20 \mathrm{a}$ 0,71. Com exceção das anomalias positivas de Eu, estes padrões assemelham-se aos THl de Condie (1981).

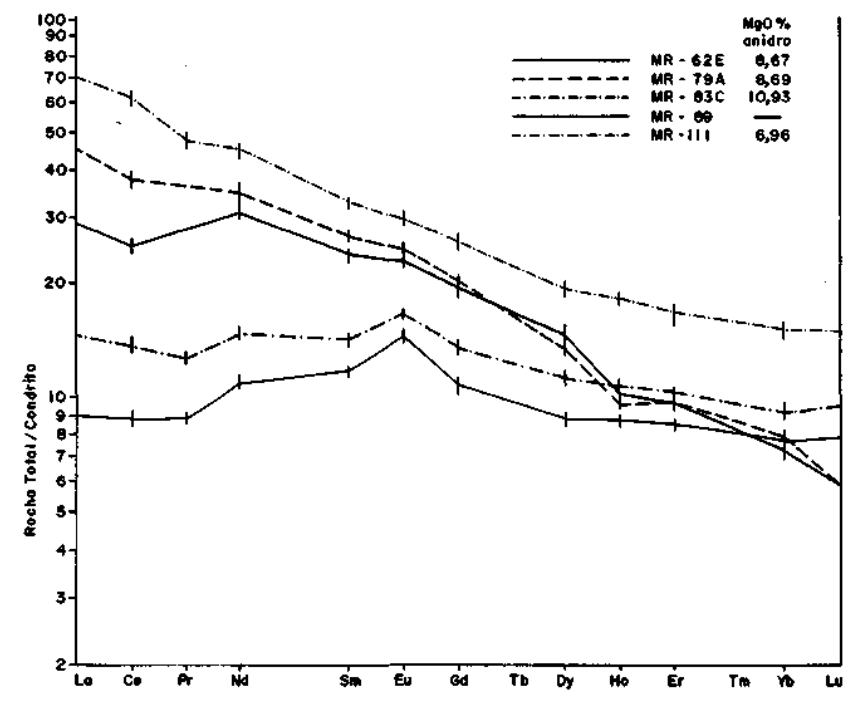

Figura 8 - Curvas de abundância dos ETR de amostras de anfibolitos e metagabros, normalizados aos condritos. Nota-se enriquecimento em terras raras leves nos anfibolitos e anomalias positivas de Eu nos metagabros, derivados da natureza cumulática dos últimos

Figure 8 - REE abundace curves of amphibolite and metagabbro samples, normalized to chondrites. Note a light rare earth element enrichment in amphibolites and Eu positive anomalies for metagabbros, the latter due to their cummulatic nature

A hipótese de origem cogenética para os metagabros e anfibolitos encontra restrições, porque não define claramente as diferenças nos padrões de ETRL, os quais são bem mais enriquecidos nos anfibolitos. Existe a possibilidade de que os anfibolitos tenham se originado de uma fonte distinta daquela dos metagabros. Estes primeiros são provenientes de um manto enriquecido em ETRL, da mesma forma que os xistos magnesianos discutidos anteriormente. Os metagabros, por outro lado, podem ter sido originados em eventos mais jovens, a partir da fusão de uma fonte já empobrecida em ETRL e outros incompatíveis (extraídos previamente pelos anfibolitos e xistos magnesianos). De qualquer modo, a origem do magma precursor dessas rochas máficas estaria ligada provavelmente a baixas porcentagens de fusão parcial do manto (Green \& Ringwood 1967).

Por outro lado, o gap composicional (11 a 17\% de MgO) entre os anfibolitos e metagabros (toleítos) e os xistos magnesianos (komatiitos e basaltos komatíticos), da sequência máfico-ultramáfica, leva a crer que esse espectro de composição está mais relacionado a diferentes quantidades de fusão parcial do que a processos de cristalização fracionada.

Os padrões de ETR, normalizados ao condrito, das rochas portadoras de olivina e/ou sepentina (MR-101 e MR-134) e do talco xisto (MR-84F) possuem formas em "U", côncavas para cima (Fig. 9), similares aos dos dunitos e harzburgitos encontrados em peridotitos alpinos (Frey 1984); porém, com concentrações mais elevadas de ETR e anomalias positivas de Eu, que os diferenciam daqueles.

Os mínimos para estas amostras são definidos pelo Ho (MR-134 e MR-101). As anomalias negativas de Ce, Ho e Er estão ligadas à alteração secundária, oriundas da serpenținização e esteatização (Sun \& Nesbitt 1978, Humphris I984). Os padrões dos perfis de abundância dos ETR, com formas de "U", e as anomalias positivas sistemáticas de Eu, para todas as amostras com valores $\mathrm{Eu} / \mathrm{Eu}^{*}$ entre 1,76 e 2,76 , podem indicar que houve fracionamento do ortopiroxênio nessas litologias. Alternantivamente, os padrões de 


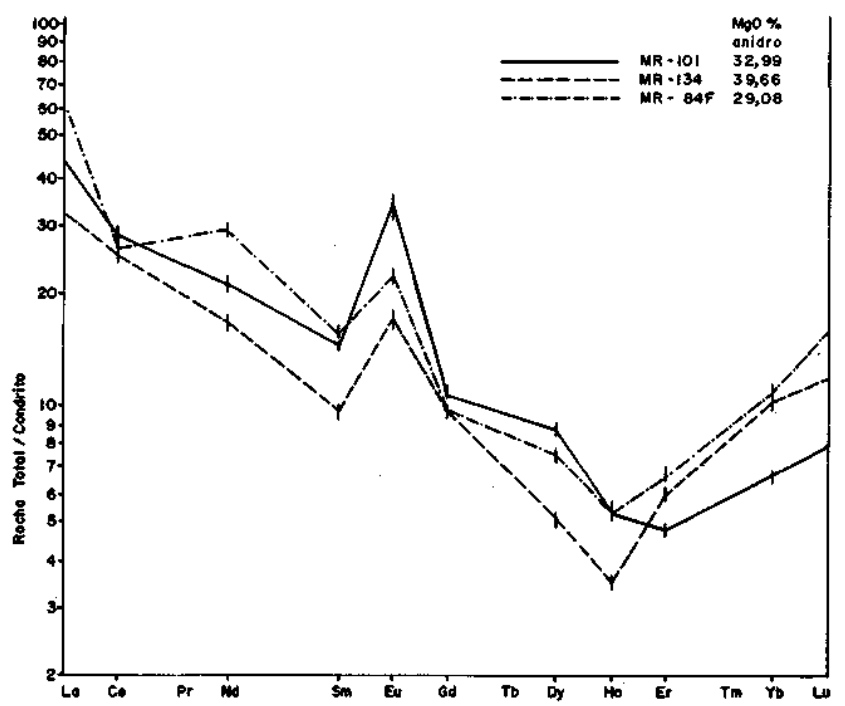

Figura 9 - Curvas de abundância dos ETR em amostras de serpentinito, olivina-talco ultramafito e clorita -antofilitatalco xisto, normalizados aos condritos. As curvas dos ETR com formas de "U" e as anomalias positivas de Eu sugerem fracionamento de ortopiroxênio nestas rochas Figure 9 - REE abundance curves of serpentinites, olivine-talc ultramafites and chlorite-anthophyllite-talc schist samples, normalized to chondrites. The REE curves with "U" form and the Eu positive anomalies suggest orthopyroxene fractionation

ETRL enriquecidos e as anomalias de Eu podem ter sido produzidos pelos processos de serpentinização e esteatização (Humphris 1984, Schrank \& Choudhuri 1989).

De qualquer modo, as abundâncias de ETR dessas rochas são próximas aos valores encontrados em olivinas, as quais contêm pequenas abundâncias de ETR total, da ordem de cinco vezes o padrão condrítico (Haskin 1984), indicando que essas amostras se originaram pelo fracionamento de olivina e ortopiroxênio, através de processos cumuláticos.

AMBIENTE TECTÔNICO As unidades litológicas da sequência máfico-ultramáfica ocorrem na forma de jazimentos, acamadados no interior dos metassedimentos, em várias escalas, indicando que estas litologias representam, ao menos em parte, derrames básico-ultrabásicos derivados de magmas de afinidade komatiítico-toleítica, conforme discutido nas seções precedentes. As intercalações de sedimentitos químicos, representados por cherts e formações ferríferas, marcam períodos de quiescência e de recorrência do vulcanismo e de sedimentação. A ausência de lavas em almofada e a ocorrência de quartzitos faz supor que as lavas extravasaram em ambientes subaquosos relativamente rasos. As espessuras das sequências de derrames, nesta região, parecem não ter sido significativas. A quantidade dos supostos derrames de basaltos komatíticos (clorita-hornblenda xistos) é aparentemente maior que a dos komatiitos. Essas relações estratigráficas são características de greenstones belts de terrenos mais jovens, da ordem de 2,7 Ga (Nisbet 1982).

O magma básico-ultrabásico (precursor dessas litologias) proveniente do manto ascendeu através de extensas e profundas fraturas, ligadas possivelmente ao fendilhamento da crosta siálica, resultante de esforços distensionais em épocas Pré-Brasilianas. É provável que as lavas tenham sido geradas em grandes profundidades, possibilitando inicialmente o fracionamento da granada, responsáveis pelos padrões empobrecidos em ETRP. Já, o fracionamento do plagioclásio em baixa pressão na crosta é responsável pelas anomalias negativas de Eu e Sr. Existem evidências claras que algumas suítes komatiíticas de terrenos mais jovens extravasaram numa crosta continental pré-existente, em regimes tectônicos extensionais (Nisbet 1982).

CONCLUSÕES Os serpentinitos e/ou olivina-talco ultramafitos, em sua maioria, correspondem a cumulados ultramáficos (komatiíticos) transformados por processos de alteração secundária. Em algumas ocorrências, os processos metassomáticos foram intensos e produziram enriquecimento residual em $\mathrm{MgO}$

Os xistos magnesianos com talco correspondem a komatiitos intensamente transformados por processos de metamorfismo aloquímico. As variações composicionais principais, neste grupo de rochas, são controladas pelo fracionamento de piroxênio (e subordinadamente olivina) e pelo metassomatismo superposto.

Os clorita e anfibólio xistos e clorita-hornblenda xistos são comparáveis a komatiitos e basaltos komatiíticos, respectivamente, deformados e metarnorfizados, sem vestígio de sua mineralogia ou textura originais. Suas variações composicionais são controladas, principalmente, pelo fracionamento do clinopiroxênio.

Os padrões e abundâncias dos elementos terras raras e razões de elementos-traço indicam que os xistos magnesianos das camadas A e B foram originados a partir de pequenas porcentagens de fusão parcial, levemente diferentes, mas de uma mesma fonte (manto) enriquecida em elementos incompatíveis. As variações composicionais no interior das camadas estão relacionadas à cristalização fracionada.

Os anfibolitos (metabasaltos) exibem padrões de fracionamento de ETR similares aos toleítos- $\mathrm{TH}_{\mathrm{z}}$ encontrados em greenstones antigos. As curvas de abundância das amostras analisadas demonstram que os metabasaltos foram gerados por cristalização fracionada de um mesmo magma.

Os padrões de enriquecimento em ETRL dos xistos magnesianos (em geral) e nos metabasaltos estão relacionado a processos de fusão seletiva, onde os primeiros líquidos extraídos do manto são ricos em elementos incompatíveis. Os metagabros, por sua vez, podem representar fusões mais jovens de um manto já empobrecido em ETRL, devido a extração prévia pelos xistos magnesianos e metabasaltos.

As amostras de xistos magnesianos, com padrões pouco enriquecidos em ETRL, perderam esses elementos durante os processos de alteração secundária. As anomalias negativas de $\mathrm{Ce}$ e $\mathrm{Eu}$, na maior parte das rochas da sequência máficoultramáfica, indicam que os derrames estiveram em contato com a água do mar e sofreram alteração submarina heterogênea antes do metamorfismo e deformação regionais.

As possíveis correlações entre as anomalias de $\mathrm{Eu}$ e a participação de plagioclásio no fracionamento dos líquidos precursores dos xistos magnesianos foram mascaradas pelos efeitos de alteração secundária que produziram anomalias negativas (predominantes) e positivas de $\mathrm{Eu}$, em quase todas as amostras estudadas. Entretanto, as anomalias negativas de Sr, em diagramas de abundâncias dos elementos incompatíveis, normalizados ao manto primitivo, constituem-se em argumentos favoráveis à hipótese da extração do plagioclásio dos líquidos precursores desses xistos.

Os teores elevados de ETRL e o enriquecimento em outros elementos incompatíveis sugerem que essas rochas foram extraídas do manto, em regimes tectônicos extensionais, através do rifteamento da crosta continental préexistente. $\mathrm{O}$ magma precursor foi provavelmente gerado em grandes profundidades crustais, com a participação de material da astenosfera.

Agradecimentos Os autores agradecem à Fundação de Amparo a Pesquisa do Estado do Rio Grande do Sul 
(FAPERGS) e ao Conselho Nacional de Desenvolvimento Científico e Tecnológico (CNPq) (Processo n ${ }^{9}$ 202453/83), pelo apoio ao desenvolvimento de pesquisas em petrologia e geoquímica no Escudo Sul-Riograndense. Agradecem, igualmente, aos geólogos Marcos A. Tedesco (UFRGS), Edu L. Santos (DNPM) e Lineu Sabóia, pelas discussões no campo, extremamente proveitosas. As sugestões e críticas realizadas pelos Prof. Dr. Alfonso Schrank (Unicamp) e Ariplínio A. Nilson (UnB), por ocasião da avaliação da dissertação de mestrado, tornaram mais qualificado o presente trabalho. Da mesma forma, os autores agradecem a Prof. Maria do Carmo Lima e Cunha (UFRGS) e aos relatores da RBG pela revisão dos originais.

\section{REFERÊNCIAS BIBLIOGRÁFICAS}

ARNDT, N.T. \& JENNER, G.A. 1986. Crustally contaminated komatiites and basalts from Kambalda, Western Austrália. Chem. Geol, 56:229-255.

ARNDT, N.T.: NALDRETT, A.J.; PYKE, D.R. 1977. Komatiitic and iron rich tholeiitic lavas of Munro Township, Northeast Ontario J. Petrol., 18:319-369.

ARNDT, N.T.; TEIXEIRA, N.A.; WHITE, W.M. 1989. Bizarre geochemistry of komatiites from Crixás Greenstone Belt, Brazil. Contrib. Mineral. Petrol., 101(2): 187-197.

BARNES, S.J. \& OFTEN, M. 1990. Ti-rich komatiites from northern Norway. Contrib. Mineral. Petrol., 105:42-54.

BESWICK, A.E. 1982. Some geochemical aspects of alteration and genetic relations in komatiites suites. In: ARNDT, N.T. \& NISBET, E.G. eds. Komatiites. London, George Allen \& Unwin. p. 283-308.

BITENCOURT, M.F. \& HARTMANN, L.A. 1984. Reconhecimento geoquímico dos xistos magnesianos da região do Passo Feio, Caçapava do Sul - RS. In: CONGR. BRAS. GEOL., 33. Rio de Janeiro, 1984 Anais... Rio de Janeiro, SBG. v. 6, p. 2607-2614.

CONDIE, K.C. 1981. Archean Greenstone Belts. Amsterdam, Elsevier. $434 \mathrm{p}$.

CULLERS, R.L. \& GRAF, J.L. 1984. Rare earth elements in igneos rocks of the continental crust: predominantly basic and ultrabasic rocks.

In: HENDERSON, P. ed. Rare Earth Element Geochemistry. Amster-

dam, Elsevier. p. $237-274$

CHEMALLE, F., Jr. 1982. Geologia da Região de Palma, São Gabriel, Rio Grande do Sul. Porto Alegre. 136 p. (Dissertação de Mestrado, IG-UFRGS)

DONALDSON, C.H. 1982. Spinifex-textured komatiites: a review of textures, mineral compositions and layering. In: ARNDT, N.T. \& NISBET, E.G. eds. Komatiites. London, George Allen \& Unwin. p. 312-244.

DUTRA, C.V. 1984. Método para determinacão de traços e sub-tracos de terras raras em rochas por espectrometria de plasma (ICP). Aplicação em petrogênese. In: CONGR. BRAS. GEOL., 33. Rio de Janeiro, 1984. Anais... Rio de Janeiro, SBG. v. 10, p. 4792-4805.

EVENSEN, N.M.; HAMILTON, P.J.; O'NIONS, R.K. 1978. Rare earth abundances in chondritic meteorites. Geochim. Cosmochim. Acta, 42:1199-1212.

FIGUEIREDO, M.C.H. \& KRONBERG, B.I. 1988. LREE-enriched komatiites from Crixás, Central Brazil. In: INTERN. CONFERENCE GEOCHEMICAL EVOLUTION OF THE CONTINENTAL CRUST. Poços de Caldas, 1988. Abstracts... Poços de Caldas, IUGS. p. 209-216.

FRAGOSO CESAR, A.R.S. 1980. O Cráton do Rio de La Plata e o Cinturão Dom Feliciano no Escudo Sul-Riograndense. In: CONGR BRAS. GEOL., 31. Balneário de Camboriú, 1980. Anais... Balneário de Camboriú, SBG. v. 5, p. 2879-2890.

FREY, F.A. 1984. Rare earth element abundances in upper mantle rocks. In: HENDERSON, P. ed. Rare Earth Element Geochemistry. Amsterdam, Elsevier. p. 153-203.

FREY, F.A.; HASKIN, L.A.: HASKIN, M.A. 1971. Rare Earth abundances in some ultramafic rocks. J. Geophys. Res., 75:2057-2070.

FRYER, B.J. 1977. Rare earth evidence in iron formations for changing Precambrian oxidation states. Geochim. Cosmochim. Acta, 41:361-367.

GARCIA, M.A.M. \& HARTMANN, L.A. 1981. Petrologia do Complexo Palma - RS. Acta Geol Leopold., 5(9):51-119.

GARMANN, L.B.; BRUNFELT, A.O.; FINSTAD, K.G.; HEIER, K.S 1975. Rare earth element geochemistry distribution in basic and ultrabasic rocks fron West Norway. Chem. Geol, 15:103-116.

GÕNI, J.C. 1962. Origine des roches ultrabasiques et serpentineuses du précambrien de Rio Grande do Sul (Brésil). Mode de gisement et minéralisations. Esc. Geol. UFRGS, 12:7-91.

GÕNI, J.C.; GOSO, H.; ISSLER, R.S. 1962. Estratigrafia e Geologia Econômica do Pré-Cambriano e Eo-Paleozóico Uruquaio e SulRiograndense. Porto Alegre, UFRGS. p. 1-105. (Avulso Esc. Geol. 3). GREEN, D.H. 1971. Composition of basaltic magma as indicators of conditions of origin: apllication to oceanic volcanism. Phil. Trans $R$. Soc. London, Serie A, 268:707-725.

GREEN, D.H. \& RINGWOOD, A.E. 1967. The genesis of basaltic magmas. Contrib. Mineral. Petrol, 15:103-190.

HARTMANN, L.A. \& NARDI, L.V.S. 1983. Contribuição à geologia da região oeste do Escudo Sul-Riograndense. In: SIMP. SUL-BRAS GEOL., 1. Porto Alegre, 1983. Atas... Porto Alegre, SBG. p. 9-18.
HASKIN, L. 1984. Petrogenetic modelling - use of rare earth elements. In: HENDENSON, P. Ed. Rare Earth Element Geochemistry. Amsterdan, Elsevier. p.115-152.

HAWKESWORTH, C.J \& O'NIONS, R.K. 1977. The petrogenesis of some Archaen volcanic rocks from southern África. J. Petrol, 18(3):487-520.

HUHN, S.R.B.; MARTINS, L.P.B.; MONTALVÃO, R.M.G. 1986. Caracterizações petrográficas, texturais e estruturais de fluxos máficoultramáficos do Greenstone Belt de Seringa, Sul do Estado do Pará. In: CONGR. BRÁS. GEOL., 34. Goiânia, 1986. Anais... Goiânia, SBG. v. 2, p. 648-662.

HUMPHRIS, S.E. 1984. The mobility of the rare earth elements in the crust. In: HENDERSON, P. ed. Rare Earth Element Geochemistry. Amsterdan, Elsevier. p. 317-342.

JAHN, B.M. \& SCHRANK, A. 1983. REE geochemistry of komatiites and associated rocks from Piumhi, southeastern Brazil. Precambrian Res., 21:1-20.

JOLLY, W T 1982. Prooressive metamorphism of komatiites and related Archean lavas of the Abitibi area, Canada. In: ARNDT, N.T. \& NISBET, E.G. ed. Komatiites. London, George Allen \& Unwin. p. $245-265$.

JOST, H. 1966. Complexos básico-ultrabásicos do Alto Rio Vacacaí, São Gabriel, Rio Grande do Sul, Brasil. Notas e Estudos, Esc. Geol, UFRGS, 1-2:55-61.

JOST, H. \& HARTMANN, L.A. 1984. Província Mantiqueira Setor Meridional. In: ALMEIDA, F.F.M. \& HASUI, Y. coord. O Pré-Cambriano do Brasil. São Paulo, Ed. Blücher. p. 345-367.

JOST, H. \& VILLWOCK, J.A. 1966. Contribuição à estratigrafia do PréCambriano no Rio Grande do Sul. Notas e Estudos, Esc. Geol, UFRGS, 1(1):13-26

KOPPE, J.C.; HARTMANN, L.A.; LISBOA, P.F.C.; MONTEIRO, R.N. 1985. Aspectos geológicos e estratigráficos do Complexo Bossoroca, São Sepe, Rio Grande do Sul. In: SIMP. SUL-BRAS. GEOL., 2. Florianópolis, 1985. Anais... Porto Alegre, SBG. p. 32-36.

KOPPE, J.C. \& HARTMANN, L.A. 1988. Geochemistry of the Bossoroca greenstone belt, southemmost Brazil. Geochim. Brasil., 2(2):167-174

LUDDEN, J.N. \& GÉLINAS, L. 1982. Trace element characteristics of komatiites and komatiitic basalts from the Abitibi metavolcanic belt of Quebec. In: ARNDT, N.T. \& NISBET, E.G. ed. Komatiites. London, George Allen \& Unwin. p. 331-346.

LUDDEN, J.N. \& THOMPSON, G. 1979. An evaluation of the behavior of the rare earth elements during the weathering of sea-floor basalt. Earth Planet. Sci. Lett., 43:85-92.

MENZIES, M.; SEYFRIED, W; BLANCHARD, D. 1979. Experimental evidence of rare earth element imobility in greenstones. Nature, 282:398-399.

MONTALVÃO, R.M.G.; LOPES, L.M.; PEREIRA, L.G.M. 1981. Petrologia dos Komatiitos de Crixás, Goiás. Goiânia, SBG/NC-O. p. 89127. (Bol. Inf. 10).

NARDI, L.V.S. \& HARTMANN, L.A. 1979. O Complexo Granulítico Santa Maria Chico do Escudo Sul-Riograndense. Acta Geol. Leopold., 3(6):45-74.

NAUMANN, M. 1985. O Complexo Vulcano-Sedimentar-Ultramáfico e Granitóides da Região de Ibaré/RS. Porto Alegre. 161 p. (Dissertacão de Mestrado, IG-UFRGS).

NESBITT, R. W. 1971. Skeletal crystal forms in the ultrabasic rocks of the Yilgarn Block, Western Austrália: evidence for an Archean ultramafic liquid. Geol. Soc. Austr. J., Sp. Publ, 3:331-347.

NESBITT, R.W. \& SUN, S. 1976. Geochemistry of Archean "Spinifex" textured peridotites and magnesian and low-magnesian tholeiites. Earth Planet. Sci. Lett., 32:443-453.

NESBITT, R.W.; SUN, S.; PURVIS, A.C. 1979. Komatiites: geochemistry and genesis. Can. Mineral, 17:165-186.

NISBET, E.G. 1982. The tectonic setting and petrogenesis of komatiites. In: ARNDT, N.T. \& NISBET, E.G. Komatiites. London, George Allen \& Unwin. p. $501-520$

NISBET, E.G.; BICKLE, M.J.; MARTIN, A. 1977. The mafic and ultramafic lavas of Belingwe Greenstone Belt, Rhodesia. J. Petrol, 18:521-563.

PADILHA, A.V.; SILVA, J.C., Jr.; OLIVEIRA, S.B. 1985. A unidade metavulcânica do Grupo Nova Lima no Córrego dos Boiadeiros: uma sequência ultramáfica-máfica na base do Supergrupo Rio das Velhos. Rev. Bras. Geoc., 15(11):74-84. 
PEREDERY, W.Y. 1979. Relationship of ultramafic amphibolites to metavolcanic rocks and serpentinites in the Thompson Belt, Manitoba. Cem. Mineral, 17:187-200.

PIPER, D.Z. 1974. Rare earth elements in the sedimentary cycle: a summary. Chem. Geol, 14(4):285-304.

PYKE, D.R.; NALDRETT, A.J.; ECKSTRAND, O.R. 1973. Archean ultramafic flows in Munro Township, Ontario. Geol. Soc. Am. Bull., 84:955-978.

REMUS, M.VD. 1990. Geologia e Geoquímica do Complexo Cambaizinho São Gabriel - RS. Porto Alegre. 267 p. (Dissertação de Mestrado, IG-UFRGS).

REMUS, M.V.D. \& HARTMANN, L.A. 1986. Geoquímica de terras raras e evolução metamórfica de xistos magnesianos e associados do Complexo Cambaizinho, São Gabriel - RS. In: CONGR. BRAS. GEOL., 34. Goiânio, 1986.Resumos e Breves Comunicações... Goiânia, SBG. Bol. 1, p. 252-253

RIBEIRO, M: BOCCHI, P.R. FIGUEIREDO, P.M., F; TESSARI, RJ. 1966. Geologia da Quadrícula de Caçapava do Sul, RS. Rio de Janeiro, DNPM/DFPM. 232 p. (Bol. 127).

RIBEIRO, M. \& FANTINEL, L. 1978. Associações petrotectônicas do Escudo Sul-Riograndense: I - tabulação e distribuição das associacões petrotectônicas do Escudo Sul-Riograndense. Iheringia, Ser. Geol., 5:19-54.

RIBEIRO, M. \& LICHTENBERG, E. 1978. Sínteșe da geologia do Escudo do Rio Grande do Sul. In: CONGR. BRAS. GEOL., 30. Recife, 1978. Anais... Recife, SBG. v. 6, p. 2451-2463.

SABOIA, L. \& TEIXEIRA, N.A. 1980. Lavas ultrabásicas da unidade basal do Greenstone Belt de Crixás - GO: uma nova classe de rochas ultrabásicas no Estado de Goiás. Rev. Bras. Geoc., 10(1):28-42.

SCHULZ, KJ 1982. Magnesian basalts from Archaen terrains of Minnesota. In: ARNDT, N.T. \& NISBET, E.G. eds. Komatiites. London, George Allen \& Unwin. p. 171-186.

SCHRANK, A. 1986. Gênese e evolução de derrames komatiíticos a clinopiroxênio-spinifex de Piumhi - MG. In: CONGR. BRAS. GEOL., 34. Goiânia, 1986. Anais... Goiânia, SBG. v. 2, p. 695-709.

SCHRANK, A. \& CHOUDHURI, A. 1989. Elementos terras raras em rochas ultramáficas do Brasil. In: FORMOSO, M.L.; NARDI, L.V.S.; HARTMANN, L.A. eds. Geoquímica dos Elementos Terras Raras no Brasil. Rio de Janeiro, CPRM-DNPM/SBG. p. 63-68

SMITH, H.S. \& ERLANK, A.J. 1982. Geochemistry and petrogenesis of komatiites from the Barberton Greenstone Belts, South Africa. In: ARNDT, N.T. \& NISBET, E.G. eds. Komatiites. London, George Allen \& Unwin. p. 347-393.

SUN, S.S. 1984. Geochemical characteristics of Archaen ultramafic and mafic volcanic rocks: implications for mantle composition and evolution. In: KRÕNER, A.; HANSON, G.N.; GOODWIN, A.M. eds. Archaen Geochemistry. Berlin, Springer. p. 99-114.
SUN, S.S. \& NESBITT, R.W. 1978. Petrogenesis of Archaen ultrabasic and basic volcanics: evidence from rare earth elements. Contrib. Mineral. Petrol., 65:301-325.

SUN, S.S.; NESBITT, R.W.; SHARASKIN, A. 1979. Geochemical characteristics of mid-ocean ridge basalts. Earth Planet. Sci. Lett. 44:119-138.

SZUBERT, C.C.; KIRCHNER, C.A.; GARCIA, C.A.; ANDREOTTI, J.L.S.; SHINTAKU, I. 1977. Projeto Cobre nos Corpos BásicoUltrabásicos e Efusivas do Rio Grande do Sul. Porto Alegre, CPRM/ DNPM. v. 2, 113 p. (Relatório Inédito).

VILJOEN, MJ. \& VILJOEN, R.P. 1969a. The effects of metamorphism and serpentinization of the volcanic and associated rocks of the Barberton region. Geol. Soc. S. Afr. Trans., Sp. Publ, 2:29-55. (Upper Mantle Project)

VILJOEN, MJ.\& VILJOEN, R.P. 1969b. The geology and geochemistry of the ultrabasic unit of the Onverwacht Group and a proposed new class of igneous rocks. Geol. Soc. S. Afr. Trans., Sp. Publ., 2:56-85. (Upper Mantle Project)

VILJOEN, MJ. \& VILJOEN, R.P. 1982. Komatiites an historical review. In: ARNDT, N.T. \& NISBET, E.G. eds. Komatiites. London, George Allen \& Unwin. p. 5-27.

VILJOEN, MJ.; VILJOEN, R.P.; PEARTON, T.N. 1982. The nature and distribution of Archaen komatiite volcanics in South A frica. In: ARNDT, N.T. \& NISBET, E.G. eds. Komatiites. London, George Allen \& Unwin. p. 53-79.

WÀNKE, H; BADDENHAUSEN, H · PALME, H; SPETTEL. B. 1974 On the-chemistry of the Allende inclusions and their origin as hightemperature condensates. Earth Planet. Sci. Lett., 23:1-17.

WHITFORD, DJ. \& ARNDT, N.T. 1979. Rare earth element abundances in a thick, layered komatiite lava flow from Ontario, Canada. Earth Planet. Sci. Lett., 41:188-196.

WILDNER, W. 1990. Caracterização Geológica e Geoquímica das Sequências, Ultramáfica e Vulcano-Sedimentares da Região da Bossoroca - RS. Porto Alegre. 170 p. (Dissertação de Mestrado, IG-UFRGS).

WOOD, D.A.; TARNEY, J.; WAVER, B.L. 1981. Trace element variation in Atlantic Ocean basalts and Proterozoic dykes from northwest Scotland: their bearing upon the nature and geochemical evolution of the upper mantle. Tectonophysics, 75:91-112.

ZARPELON, PR 1986. Geologia Estrutural Estratigrafia e Petrologia de uma parte do Greenstone Belt Cerrito do Ouro, Município de São Sepé/RS. Porto Alegre. 215 p. (Dissertação de Mestrado, IG-UFRGS).

MANUSCRITO A716

Recebido em 6 de fevereiro de 1992 Revisão do autor em 23 de agosto de 1993 Revisão aceita em 27 de setembro de 1993 